\title{
Microwave-assisted Synthesis of Amine Functionalized Mesoporous Polydivinylbenzene for $\mathrm{CO}_{2}$ Adsorption
}

\author{
Tahereh Jafari, ${ }^{a}$ Ehsan Moharreri ${ }^{\mathrm{a}}$, Panteha Toloueinia ${ }^{\mathrm{a}}$, Alireza Shirazi Amin ${ }^{\mathrm{b}}$, Sanjubala Sahoo ${ }^{\mathrm{a}, \mathrm{c}}$, Nasser \\ Khakpash $^{\mathrm{a}, \mathrm{c}}$, Iman Noshadi ${ }^{\mathrm{de,}, \mathrm{f}}$, S. Pamir Alpay ${ }^{\mathrm{a}, \mathrm{c}}$ and Steven L. Suib ${ }^{\mathrm{a}, \mathrm{b}, \mathrm{c}}$ * \\ ${ }^{a}$ Institute of Materials Science, University of Connecticut, 97 North Eagleville Road, Storrs, Connecticut 06269-3136, United \\ States \\ ${ }^{\mathrm{b}}$ Department of Chemistry, University of Connecticut, 55 North Eagleville Road, Storrs, Connecticut 06269-3060, United States \\ ${ }^{\mathrm{c}}$ Department of Materials Science and Engineering, University of Connecticut, 97 North Eagleville Road, Storrs, Connecticut \\ 06269-5233, United States \\ ${ }^{\mathrm{d}}$ Department of Chemical and Biomolecular Engineering, University of Connecticut, U-3222, 191 Auditorium Road, Storrs, CT \\ 06269-3222, United States \\ ${ }^{\mathrm{e}}$ Department of Chemical Engineering, Rowan University, Glassboro, NJ, United States \\ ${ }^{\mathrm{f}}$ Harvard-MIT Health Science and Technology, Massachusetts Institute of Technology, 77 Massachusetts Avenue, Cambridge, \\ 02139, United States. \\ *Corresponding author, Email: steven.suib@uconn.edu
}

\begin{abstract}
We report microwave assisted synthesis of a series of highly hydrophobic porous organic polymers of poly divinylbenzene (PDVB), for the first time, which were modified by amine-rich co-monomers of vinyl imidazole (VI) and vinyl triazole (VT) resulting in PDVB-VI and PDVB-VT adsorbents. There is an optimum amount of incorporated co-monomer and initiator which led to high adsorptive activity of the material towards $\mathrm{CO} 2$. Atmospheric $\mathrm{CO} 2$ adsorption was enhanced by the addition of amine moieties while maintaining an optimum surface area and pore volume. A certain amount of initiator led to better incorporation of VT monomer while surface area and pores remain accessible. A maximum $\mathrm{CO} 2$ adsorption of 2.65 mmolg- 1 at $273 \mathrm{~K} / 1$ bar was achieved for triazole based adsorbent (PDVB-VT) with $0.7 \mathrm{~g}$ of VT and $0.07 \mathrm{~g}$ of initiator. In comparison with a non-functionalized material (PDVB) with 1.2 mmolg-1 CO2 uptake, the adsorption efficiency was enhanced more than twice. The adsorbent maintained its efficiency up to seven cycles. Theoretical modeling confirms the active site is nitrogen on the imidazole/ triazole ring and that incorporation of VT to the polymeric networks enhanced the adsorptive properties better than vinyl imidazole (VI) due to more active sites.
\end{abstract}

\section{Introduction}

Adversely contributing to climate changes, greenhouse gases (GHG) emission has been a serious environmental concern. Carbon dioxide $\left(\mathrm{CO}_{2}\right)$ being the predominant part of GHG, primarily comes from fossil fuel consumption in the transportation, energy generation, and industrial sectors[1,2]. GHG emission results in increasing the earth surface temperature which is predicted to be as high as $3^{\circ} \mathrm{C}$ by the year 2100 (according to IPCC report)[3,4]. Mitigation of $\mathrm{CO}_{2}$ emission by an alternative source of energy [5] needs significant changes to the current infrastructure of carbon based power plants. Therefore, $\mathrm{CO}_{2}$ capture and storage techniques (CCS) could be applied to the current fossil-fuelled power plants to tackle the problem in the short term[6]. Among various approaches in CCS techniques[7] the postcombustion methodology shows advantages over the others[8].

While absorption by amine-solution has drawbacks of corrosion, considerable energy loss, and inefficient regeneration, this has been the most widely adopted strategy[9]. Adsorption by solids provides some 
advantages such as (i) high $\mathrm{CO}_{2}$ capture capacity, (ii) low energy requirement of adsorbent regeneration, (iii) adsorbent stability, (iv) fast kinetics, (v) easy handling, and (vi) efficiency under flue gas moisture[10,11]. On the atomic scale, polarizability or the quadrupole moment of the adsorbent functional site plays a significant role in the selective capture of $\mathrm{CO}_{2}$ during physisorption[12,13]. However, for chemisorptive adsorption, selectivity is obtained based on chemical interactions between individual components of the gas mixture and surface functionalities of the adsorbent[14]. A regeneration step should follow the adsorption to recover the solid adsorbent. To regenerate the adsorbents a pressure/vacuum swing adsorption (PSA/VSA) and temperature swing adsorption (TSA) procedure could be employed[15,16].

An efficient solid $\mathrm{CO}_{2}$ adsorbent needs high adsorption capacity and selectivity, high stability, scalability, low moisture sensitivity, and low energy of regeneration[17]. Several porous adsorbents have been evaluated for $\mathrm{CO}_{2}$ capture including alkaline earth metal oxides[18], porous carbons[19], silica[20,21], zeolites[22], metal organic frameworks (MOFs)[23], porous organic frameworks (POFs),[24] and nanoporous organic polymers (NOPs)[25]. Chemical adsorption of $\mathrm{CO}_{2}$ by alkaline earth metal oxides and metal salts at high temperatures requires high energy for regeneration[26-28]. Physical adsorbents like activated carbons (ACs) with advantages of prevalent precursor materials, hydrophobicity, and low heat of adsorption, still have the challenges of low selectivity and capacity[1]. Moreover, silicas and zeolites have been widely used as adsorbents to capture many impurities[29,30] especially $\mathrm{CO}_{2}[22,31]$. Zeolites capture the $\mathrm{CO}_{2}$ molecules very rapidly with high chemical and thermal stability[32]. However, the moisture sensitivity, the low selectivity and high energy of regeneration has limited their application[33-35]. MOFs of $\mathrm{M}_{2}$ (dobdc) have shown the highest $\mathrm{CO}_{2}$ capacities of 5-8 $\mathrm{mmolg}^{-1}(\mathrm{M}=$ $\mathrm{Mg} / \mathrm{Co} / \mathrm{Ni} / \mathrm{Zn}$ )[36], though $\mathrm{M}_{2}$ (dobdc) is highly sensitive toward moisture resulting in much lower capacity (16-85\% drop in capacity) in the presence of moisture[37]. Recently, a perfluorinated covalent triazine-based framework (FCTF-1) has been designed for selective $\mathrm{CO}_{2}$ capture which is a moisture resistant adsorbent[38]. However, synthesis of fluorinated compounds is expensive and dangerous. To address low selectivity of widely used adsorbents of ACs and zeolites, different functionalities such as carboxylic, sulfonic, and amine groups have been applied to enhance $\mathrm{CO}_{2}$ adsorption[39,40]. Based on loading methods of functional groups which mainly involve amines, there are two categories of adsorbents; amine-impregnated[41,42] and amine-grafted[43,44] materials. Impregnated adsorbents are easy to synthesize and provide high capacity. However, such materials have several drawbacks like blockage of support surface area and pores by increasing amine-loading, decomposition of loaded amines upon heating during $\mathrm{CO}_{2}$ capture, and high diffusion resistivity[45]. Amine grafting by chemical reaction provides higher thermal stability for the adsorbent[43,46]. Recently, functional groups like N-donor Lewis base sites such as in organic amines have more tendency to adsorb $\mathrm{CO}_{2}$ molecules[47]. Amine functionality provides Lewis base sites with lone pair electrons which coordinate favourably with $\mathrm{CO}_{2}$ molecules[48] with several triazine-based polymeric adsorbents being developed for $\mathrm{CO}_{2}$ adsorption[4951]. Amine functionalized silicas have been shown to experimentally and theoretically influence the $\mathrm{CO}_{2}$ adsorption mechanism[52] by the formation of intermolecular ammonium carbamates with primary amines, while being stabilized with secondary amines by forming carbamic acid.

Porous polymers provide several advantages of (i) clear design of the high surface area and well-defined porosity, (ii) easy processing, (iii)and light elemental composition which provide weight advantages[53]. Recently, several porous polymers (mesoporous or microporous) have been developed for $\mathrm{CO}_{2}$ capture[54,55]. Amine modified porous polymers have also been drawn up to adsorb $\mathrm{CO}_{2}$ more 
efficiently[56,57]. The new class of triazine-based microporous frameworks with high thermal and chemical stability have been developed through the Sonogashira-Hagihara reaction using Pd-based catalysts to improve $\mathrm{CO}_{2}$ adsorption of polymeric materials[51]. In 2013, Liebl and Senker synthesized a series of triazine-based porous polyimide polymers via condensation reactions which resulted in microporous polymeric networks with the highest $\mathrm{CO}_{2}$ uptake of $2.45 \mathrm{mmolg}^{-1}$ at $273 \mathrm{~K}$ and 1 bar[49]. Later on, Wang et al. developed ultramicropores and nitrogen-rich covalent triazine-based frameworks for $\mathrm{CO}_{2}$ capture with the capacity of $2.61 \mathrm{mmolg}^{-1}$ at $298 \mathrm{~K}$ for the adsorbent with $27.64 \%$ amine loading[24].

Previously, PDVB based polymers have been synthesized with various morphologies and textural properties including monodispersed microspheres[58], macroporous[59], nanoporous sheets[60] and as mesoporous materials[61]. Biogas purification from siloxane impurities has been conducted by highly hydrophobic mesoporous PDVB based materials[61,62]. The effect of synthesis parameters such as various solvent effects (type and ratio of solvent mixture),[63] synthesis temperature,[64] and initiator amount[65] have also been studied on textural properties of PDVB-based materials. Feng et al. have synthesized mesoporous poly-ionic liquids of divinylbenzene copolymerized with alkylvinylimidazolium (P(DVB-IL))[65], for which decreasing the amount of initiator enhanced the textural properties (higher surface area). Recently, PDVB-based materials which were modified by ionic liquids (ILs)[65] or amine rich monomers[66,67] for $\mathrm{CO}_{2}$ adsorption. PDVB functionalized with ionic liquids of alkylvinylimidazolium salt showed $\mathrm{CO}_{2}$ uptake of $0.5 \mathrm{mmolg}^{-1}$ at 298K/1 bar[65]. PDVB was also functionalized with co-monomer of tartardiamide under long hydrothermal reaction which resulted in porous polymers with $\mathrm{CO}_{2}$ adsorption capacity of $8.76 \mathrm{mmolg}^{-1}$ at $273 \mathrm{~K}$ under high pressure of $3 \mathrm{bar}[66]$. Copolymerization of divinylbenzene and triallylamine under solvothermal conditions, also resulted in amine modified porous polymers with $\mathrm{CO}_{2}$ uptake of $19.5 \mathrm{mmolg}^{-1}$ at $273 \mathrm{~K}$ and high pressure of 3 bar[67]. However, there are no reported works on $\mathrm{CO}_{2}$ adsorption by non-functionalized PDVB . Therefore, the roles of functional groups were not clearly understood.

All previously reported synthesis procedures of PDVB-based materials have been obtained by long hydrothermal reactions. However, microwave assisted synthesis of polymeric materials provides several advantages such as a uniform and fast heating process, non-contact, and highly specific heating $[68,69]$. Very recently a comparative study on thermal- and microwave assisted synthesis has been reported by Raj et al in which higher molecular weight polymers were obtained in shorter reaction time by a microwave approach [70]. Hoogenboom et al [71] have reported batch mode microwave-assisted polymerization with up to 250 fold scale up. Recent advances in flow mode microwave-assisted polymerization[72,73] have proved that the process will become less challenging from a commercial production perspective. Herein we study $\mathrm{CO}_{2}$ uptake performance both experimentally and theoretically for non-functionalized and amine functionalized hydrophobic mesoporous poly divinylbenzene (PDVB) which were synthesized for the first time by microwave heating. The effect of amine type and amount of incorporation into the porous structure of the polymer and the effect of initiator amount were studied on the textural and adsorptive properties of the developed adsorbents. Theoretical calculations were conducted to enhance the understanding of the nature of the interactions between substrate and the adsorbates.

\section{Experimental}


Materials. Divinylbenzene (technical grade, 80\%) 1-vinylimidazole (VI), 1-Vinyl-1,2,4-triazole (VT), 2,2'-azobis(2-methylpropionitrile) (AIBN), and dimethylformamide (DMF) were purchased from SigmaAldrich. Solvents and materials were used as received.

Synthetic Procedures. In a typical run, non-functionalized PDVB was obtained through a microwave assisted procedure as follows. A Biotage initiator microwave synthesizer was used in this study which has been recently employed for inorganic nanoparticle synthesis[74]. The microwave reactor has a built-in computer and touch screen with the ability to reach a maximum temperature of $250^{\circ} \mathrm{C}$ with a heating rate of $2-5^{\circ} \mathrm{C}$ min-1 providing a maximum pressure of 20 bars with power of $400 \mathrm{~W}$. Divinylbenzene (DVB) $(2 \mathrm{~g})$ in $20 \mathrm{ml}$ of organic solvent of dimethylformamide (DMF) were mixed. After the addition of initiator, 2,2'-Azobis(2-methylpropionitrile) (AIBN) $(0.07 \mathrm{~g})$, the solution was stirred for $3 \mathrm{~h}$ at room temperature followed by transferring to a capped microwave vial and treated at $165^{\circ} \mathrm{C}$ for $2 \mathrm{~h}$. The amine functionalized PDVB materials were synthesized similarly except with addition of amine containing comonomers such as vinyl imidazole (VI) or vinyl triazole (VT). The type of co-monomer, amount of comonomer, and initiator (AIBN) were varied to obtain an efficient $\mathrm{CO}_{2}$ adsorbent. The obtained polymers with co-monomer of VI or VT are called PDVB-VI or PDVB-VT, respectively. Figure S1 shows the schematic illustration of PDVB, PDVB-VI, and PDVB-VT. The various amounts of VT incorporated into PDVB resulted in PDVB-VTx where $x$ is the weight of co-monomer of VT $(x=0.2-0.9 \mathrm{~g})$. Furthermore, the samples with varied amounts of initiator are labelled as PDVB-VT-INy where y represents the weight of AIBN ( $\mathrm{y}=0.0065-0.09 \mathrm{~g})$.

Materials Characterization. The Brunauer, Emmett, and Teller (BET) specific surface area was determined using a $\mathrm{N}_{2}$ sorption method. Fourier transform infrared spectroscopy (FTIR) spectra were obtained with a Bruker 66V FTIR spectrometer. X-ray photoelectron spectroscopy (XPS) was carried out to prove further the presence of amine functionalities for both PDVB-VT and PDVB-VI using a PHI 595 multiprobe system using a monochromatic $\mathrm{Al} \mathrm{K \alpha}$ source $(20 \mathrm{~mA}, 14 \mathrm{kV})$. The morphology of amine rich polymers was determined by scanning electron microscopy (SEM) using an FEI Nova NanoSEM 450. Samples were coated to decrease charging with an Au-Pt alloy with a Polaron model E5100 instrument.

$\mathrm{CO}_{2}$ Adsorption. The main Evaluations of $\mathrm{CO}_{2}$ adsorption of PDVB and amine-functionalized PDVB were conducted with a Quanta Chrome (autosorb iQ2) under atmospheric pressure. To calculate the isosteric heat of adsorption $\left(\mathrm{Q}_{\mathrm{st}}\right)[75,76]$ based on the Clausius-Clapeyron relation (equation 1), the adsorption was performed at two different temperatures (Figure S2):

$$
Q_{s t}=R\left[\frac{T_{2} \times T_{1}}{T_{2}-T_{1}}\right] \times \operatorname{Ln}\left[\frac{P_{1}}{P_{2}}\right](1)
$$

The where $R$ is the universal gas constant; $T_{2}$ and $T_{1}$ are two different temperatures which are considered to be 298 and $273 \mathrm{~K} ; P_{2}$ and $P_{1}$ are the partial pressures at the same amounts of adsorbed $\mathrm{CO}_{2}$ for $T_{2}$ and $T_{1}$. Moreover, the hysteresis loop in the adsorption-desorption of $\mathrm{CO}_{2}$ (Figure $\mathrm{S} 3$ ) provides information on the adsorption pathway if the physisorption is more dominant or chemisorption which is obtained by calculating the isothermal adsorbate retention (IAR)[77,78] based on the difference between $\mathrm{CO}_{2}$ adsorbed and desorbed at a certain pressure:

$$
\operatorname{IAR}\left(\mathrm{mmol.} \mathrm{g}^{-1}\right)=C_{\text {des }}-C_{a d s}(2)
$$


$C_{a d s}$ is the equilibrium amount of adsorbed $\mathrm{CO}_{2}$ at a certain pressure, and $C_{d e s}$ is the equilibrium amount of adsorbed $\mathrm{CO}_{2}$ at the same pressure on the desorption isotherm. The recyclability of the adsorbents was evaluated by heating at low temperatures of less than $100^{\circ} \mathrm{C}$. Then, at least seven cycles of adsorption and regeneration will be carried out by the most efficient adsorbent.

Computational Methodology. Ab initio calculations using density functional theory are performed for $\mathrm{CO}_{2}$ adsorption on PDVB, PDVB-VI, and PDVB-VT employing the plane wave pseudo-potential method. The Generalized Gradient Approximation (GGA) parameterized by Perdew-Burke-Ernzhof (PBE)[79] is used for the exchange-correlation functional. Vienna ab initio Simulation Package (VASP)[80] is employed with the projector-augmented wave (PAW)[81] method for the electron-core interactions. Finite systems with large enough simulation box of sizes $(17 \times 34 \times 34) \AA^{3}$ : PDVB, $(22 \times 40 \times 22) \AA^{3}$ : PDVB-VI and $(20 \times 40 \times 26) \AA^{3}$ : PDVB-VT are considered to minimize the interaction with its periodic images. All calculations are performed with plane wave cut-off energy of $800 \mathrm{eV}$. The integration over the Brillouin zone is done at one k-point, i.e., the $\Gamma$-point only. The geometry optimization is done using the conjugate gradient method and the total energy convergence criteria are taken as $10-6 \mathrm{eV}$. The binding energy $\left(E_{a d s}\right)$ of $\mathrm{CO}_{2}$ on the polymer is defined as:

$$
E_{a d s}\left(\mathrm{CO}_{2}\right)=E\left(\mathrm{CO}_{2}\right)+E(P D V B)-E\left(\mathrm{CO}_{2}-\mathrm{PDVB}\right)
$$

where $E\left(\mathrm{CO}_{2}\right), E(P D V B)$, and $E\left(\mathrm{CO}_{2}-\mathrm{PDVB}\right)$ are total energies of free $\mathrm{CO}_{2}$, the polymer, and the $\mathrm{CO}_{2}-$ PDVB complex, respectively. The binding energy of the second $\mathrm{CO}_{2}$ molecule is calculated using:

$$
E_{\text {ads }}\left({ }^{\text {second }} \mathrm{CO}_{2}\right)=E\left(\mathrm{CO}_{2}\right)+E\left({ }^{\text {first }} \mathrm{CO}_{2}-\mathrm{PDVB}-\mathrm{X}\right)-\mathrm{E}\left(2 \times \mathrm{CO}_{2}-\mathrm{PDVB}-\mathrm{X}\right)
$$

where $E\left(\mathrm{CO}_{2}\right), E$ (first $\left.\mathrm{CO}_{2}-\mathrm{PDVB}-\mathrm{X}\right), \mathrm{E}\left(2 \times \mathrm{CO}_{2}-\mathrm{PDVB}-\mathrm{X}\right)$, are total energies of the free $\mathrm{CO}_{2}$, adsorbed $\mathrm{CO}_{2}$-copolymer complex, and two $\mathrm{CO}_{2}$-PDVB-X complexes. $\mathrm{X}$ refers to the co-monomer of VT or VI.

\section{Results}

$\mathbf{N}_{2}$ Adsorption-Desorption (BET). Textural properties of MW-assisted PDVB-based materials were investigated based on BET methods. Figure 1 displays the $\mathrm{N}_{2}$ adsorption-desorption isotherms of various porous PDVB materials synthesized under different conditions of co-monomer with different nitrogen densities (1a), amount of co-monomer (1b) and amount of initiator (1c).

Co-monomer decreased the surface area from $789 \mathrm{~m}^{2} \mathrm{~g}^{-1}$ for PDVB to 649 and $646 \mathrm{~m}^{2} \mathrm{~g}^{-1}$ for PDVB-VI and PDVB-VT, respectively (Figure 1a). Similarly, the pore volume reduced from 0.97 to 0.82 and 0.81 $\mathrm{ccg}^{-1}$ after introducing VI and VT to the PVDB. Figure $1 \mathrm{~b}$ displays BET isotherms of PDVBs with different amounts of triazole based-co-monomer. The higher level of co-monomer incorporation into the PDVB led to the lower surface area and pore volume. The surface area of non-functionalized PDVB (no co-monomer) was dropped from 789 to $500 \mathrm{~m}^{2} \mathrm{~g}^{-1}$ for the maximum amount of VT (PDVB-VT0.9). Besides, the amount of initiator was optimized by varying the AIBN from 0.0065 to $0.09 \mathrm{~g}$ which resulted in PDVB-VT-IN0.0065 to PDVB-VT-IN0.09 (Figure 1c). Increasing the amount of initiator led to more incorporation of VT into PDVB structure which resulted in less surface area. Since polymerization did not occur for the lowest amount of AIBN (PDVB-VT-IN0.0065), there is no isotherm for this sample in Figure 1c. 
Fourier Transform Infrared Spectroscopy (FTIR). Figure 2 displays the IR bands of PDVB in comparison with the amine functionalized ones. The existence of $\mathrm{C}-\mathrm{N}$ bands in the porous aminefunctionalized PDVB was observed which confirmed the successful integration of VI and VT into PDVB.

IR bands of PDVB in Figure 2a, indicates the characteristic bands of benzene rings at $700-750 \mathrm{~cm}^{-1}$ And the benzene $\mathrm{C}=\mathrm{C}$ stretching vibration bands at 1500 and $1600 \mathrm{~cm}^{-1}$ [67]. The IR bands at $2920 \mathrm{~cm}^{-1}$ and $3030 \mathrm{~cm}^{-1}$ are related to aliphatic $\mathrm{C}-\mathrm{H}$ stretching vibrations and aromatic $\mathrm{C}-\mathrm{H}$ stretching vibrations, respectively. For PDVB-VI and PDVB-VT, both aliphatic and aromatic C-N bands were detected in the range of $1020-1240 \mathrm{~cm}^{-1}$ and $1250-1360 \mathrm{~cm}^{-1}$ [60] (Figure 2b).

X-ray photoelectron Spectroscopy (XPS). The Incorporation of VI and VT co-monomers into PDVB was evaluated by XPS (Figure 3). Survey plots of PDVB materials indicated the existence of amine functionalities in the polymer surface (Figure S4).

Figure 3(a-b) indicates the high-resolution peaks on carbon and nitrogen. High-resolution spectra of $C$ 1s and $\mathrm{N}$ 1s for both PDVB-VI and PDVB-VT were taken using a $50 \mathrm{eV}$ passing energy. The instrument was calibrated to give an $\mathrm{Au} 4 \mathrm{f7} / 2$ metallic gold binding energy of $83.96 \mathrm{eV}$ [82]. To insure the cleanliness of the standard calibration sample, a gold foil was argon ion bombarded and spectral data were subsequently recorded over the full energy range., $\mathrm{C} 1 \mathrm{~s}$ and $\mathrm{N}$ 1s spectra were deconvoluted using CasaXPS software (version 2.3.12). High-resolution spectra of $\mathrm{C} 1 \mathrm{~s}$ and $\mathrm{N} 1 \mathrm{~s}$ for PDVB-VI were collected to reveal its atomic components. Deconvoluted C 1s for PDVB-VI showed C=N and C-N peaks at $286.8 \mathrm{eV}$ and $285.7 \mathrm{eV}$, respectively. Although the deconvolution pattern and binding energies of synthetic peaks of $\mathrm{C} 1 \mathrm{~s}$ in PDVB-VI resembled the corresponding one in PDVB-VT, the high-resolution spectrum of $\mathrm{N}$ 1s in PDVB-VI showed a lower number of synthetic peaks. In the C1s spectrum of PDVBVT, five different areas were resolved which indicated different types of carbon atoms in PDVB-VT. The peak at $284.8 \mathrm{eV}$ was assigned to adventitious carbon and all other peaks were referenced to that one[83]. The peaks at 285.8 and $287.0 \mathrm{eV}$ correspond to $\mathrm{C}=\mathrm{N}$ and $\mathrm{C}-\mathrm{N}$, respectively[84]. The ??-??* transition $(291.6 \mathrm{eV})$ which is a characteristic shake-up line in aromatic compounds emphasized the presence of aromatic rings in the final product[85]. The $\mathrm{N}$ 1s spectrum in PDVB-VI was deconvoluted into only two peaks. The synthetic peak appeared at $399.23 \mathrm{eV}$ and showed the contribution of imine nitrogen in PDVB-VI. The $\mathrm{sp}^{3}$ nitrogen was also assigned to the peak appeared at $400.91 \mathrm{eV}[86]$. However, the highresolution spectrum of $\mathrm{N} 1 \mathrm{~s}$ of PDVB-VT was deconvoluted using three peaks. Binding energies of 398.72, 399.75, and 401.10 eV belonged to $\mathrm{C}=\mathrm{N}-\mathrm{N}, \mathrm{C}=\mathrm{N}-\mathrm{N}$, and $\mathrm{C}-\mathrm{N}-\mathrm{N}$, respectively.

Scanning Electron Microscopy (SEM). Figure 4 shows SEM images of PDVB and the amine functionalized materials. This indicates porosity in the polymeric structures of PDVB materials which are ideal for fast diffusion of gas molecules.

$\mathrm{CO}_{2}$ Adsorption. All synthesized PDVB adsorbents (various co-monomers, different amounts of comonomer, and changing initiator amounts) were evaluated under similar conditions to obtain $\mathrm{CO}_{2}$ adsorptive capacities at a pressure of 1 bar. Table 1 and Figure 5 represent the $\mathrm{CO}_{2}$ adsorptive properties of all PDVB adsorbents at $273 \mathrm{~K}$ and atmospheric pressure. Table 1a and Figure 5a indicate the effect of amine functionalization of PDVB through VI and VT incorporation (where the amount of initiator (AIBN) is constant $0.07 \mathrm{~g}$ ). Although surface area and pore volume were reduced by co-monomer insertion, the $\mathrm{CO}_{2}$ adsorption capacity of PDVB was increased by the factors of 1.9 and 2.2 for VI and $\mathrm{VT}$, respectively. Table $1 \mathrm{~b}$ shows that the optimum level of VT was obtained at $0.7 \mathrm{~g}$. The lower amount 
of VT $(0.2 \mathrm{~g})$ led to very few $\mathrm{CO}_{2}$ enhancements that could be in the range of error which is demonstrated in Figure $5 \mathrm{~b}$ (the amount of initiator (AIBN) is constant and equal to $0.07 \mathrm{~g}$ ). Therefore, a small amount of VT has a negligible effect on the $\mathrm{CO}_{2}$ adsorption capacity of PDVB adsorbent.

Table 1c and Figure 5c show the effect of initiator (AIBN) on the textural properties and $\mathrm{CO}_{2}$ adsorptive characteristics. At a very low amount of AIBN (0.0065 g), polymerization did not occur. By increasing the initiator amount to $0.03 \mathrm{~g}$, the highest surface area $\left(815 \mathrm{~m}^{2} \mathrm{~g}^{-1}\right)$ and pore volume $\left(1.9 \mathrm{ccg}^{-1}\right)$ was obtained. More addition of initiator deteriorates the textural properties. Regarding $\mathrm{CO}_{2}$ uptake, by increasing the initiator amount, the adsorption efficiency improved then declined ( $\mathrm{IN}=0.09 \mathrm{~g}$ ). Initiator helps the incorporation of VT into the polymer during polymerization due to an increase of $\mathrm{CO}_{2}$ uptake while the surface area was reduced. Therefore, the addition of more AIBN led to involving more VT monomers onto the surface of the porous polymer. Consequently, there is an optimum point for initiator amount $(0.07 \mathrm{~g})$ in which high surface area and high amount of VT were maintained at the same time to obtain the highest $\mathrm{CO}_{2}$ uptake.

Figure 6 illustrates the selectivity of $\mathrm{CO}_{2}$ capture over $\mathrm{N}_{2}$ at $273 \mathrm{~K}$ for PDVB and amine functionalized materials. All PDVB based adsorbents have negligible $\mathrm{N}_{2}$ uptake at $273 \mathrm{~K}$.

Based on the $\mathrm{CO}_{2}$ adsorptive isotherms of PDVB materials under two temperatures of 273 and $298 \mathrm{~K}$, the isosteric heat of adsorption $\left(\mathrm{Q}_{\mathrm{st}}\right)$ was calculated using the Clausius-Clapeyron relation (equation 1). Figure $7 \mathrm{a}$ shows the range of heat of adsorption for PDVB (20-35 $\left.\mathrm{KJmol}^{-1}\right)$ decreased by integration of VI to the structure (25-35 $\left.\mathrm{KJmol}^{-1}\right)$ and increased by VT incorporation $\left(17-35 \mathrm{KJmol}^{-1}\right)$.

The energy of adsorption sites could be estimated based on the hysteresis in the adsorption-desorption isotherms of $\mathrm{CO}_{2}$ which is calculated based on isothermal adsorbate retention (IAR) (equation 2) which is shown in Figure $7 \mathrm{~b}$. Retained $\mathrm{CO}_{2}$ during desorption (IAR) occurred more at low pressures, and the $\mathrm{CO}_{2}$ amount is minuscule which confirms easy regeneration of PDVB adsorbents. The onset pressures of IAR were obtained through extrapolation of two rising and falling regions of IAR for PDVB, PDVB-VI, and PDVB-VT which were $0.27,0.32$, and 0.35 bar respectively. The larger onset pressure implies a higher energy of active sites[78]. This indicates that amine incorporation led to the formation of more adsorption sites.

Computational Findings. To determine the active site of the adsorbents, a $\mathrm{CO}_{2}$ molecule is placed at several inequivalent sites of the PDVB polymer, where $\mathrm{CO}_{2}$ attaches itself to one of the benzene rings and the $\mathrm{C}-\mathrm{C}$ chain. Among these two configurations, $\mathrm{CO}_{2}$ shows relative stability on the benzene ring of PDVB as shown in Fig. 9 (a) with a binding energy of $0.11 \mathrm{eV}$ calculated using equation 3 . The distance of $\mathrm{O}\left(\mathrm{CO}_{2}\right)$ from the benzene ring of the polymer is calculated to be $3.87 \AA$. While the adsorbed $\mathrm{CO}_{2}$ is slightly bent with bond angle $0.70^{\circ}$ as compared to the linear free $\mathrm{CO}_{2}$, the average $\mathrm{C}-\mathrm{O}$ bond length (dC$\mathrm{O})$ remains almost the same relative to the free standing $\mathrm{CO}$. For the copolymers of vinylimidazol (PDVB-VI) and vinyl triazole (PDVB-VT) $\mathrm{CO}_{2}$ molecule is adsorbed on several sites of these copolymers. Figure 1 (b-c) shows the optimized structures of $\mathrm{CO}_{2}-(\mathrm{PDVB}-\mathrm{VI}, \mathrm{PDVB}-\mathrm{VT})$ complexes. For both polymers, $\mathrm{CO}_{2}$ prefers to adsorb near the $\mathrm{N}$-site of the copolymer with binding energies of 0.15 $\mathrm{eV}$ and $0.19 \mathrm{eV}$ for PDVB-VI and PDVB-VT, respectively. The difference in the binding energy can be due to the different adsorption orientation of $\mathrm{CO}_{2}$ on the imidazole/triazole ring. For the PDVB-VI case, $\mathrm{CO}_{2}$ adsorbs almost parallel to the imidazole ring with an average vertical distance of $3.65 \AA$ from $\mathrm{C}\left(\mathrm{CO}_{2}\right)$ to the imidazole ring. For the PDVB-VT case, $\mathrm{CO}_{2}$ remains almost along the plane of the triazole 
rings with a horizontal distance of $2.89 \AA$ from $\mathrm{C}\left(\mathrm{CO}_{2}\right)$ to one of the nitrogen atoms. The adsorption energies on the copolymers are larger compared to the PDVB polymer and stronger on PDVB-VT. This finding is in agreement with the experimental results. Due to enhanced binding strengths on the copolymers relative to PDVB, the $\mathrm{CO}_{2}$ molecule shows increased bending (1.74 ${ }^{\circ}$ PDVB-VI, $3.28^{\circ}$ : PDVB-VT) as compared to free $\mathrm{CO}_{2}$ with no significant change in $\mathrm{dC}(\mathrm{C}-\mathrm{O})$. However, the adsorption sites of the polymers exhibit some local charges as shown in Figure 8(a-c) in which Bader charge analysis was used[87]. To probe the adsorption capacity, we added a second $\mathrm{CO}_{2}$ molecule on different sites of PDVB-VI and PDVB-VT with $\mathrm{CO}_{2}$ co-adsorbed. Various configurations are possible with the added $\mathrm{CO}_{2}$ molecules such as dimerization[88] or odd clusters[89] as pointed out in previous literature. However here we only considered $\mathrm{CO}_{2}$-adsorbent interactions. For the adsorption of the second $\mathrm{CO}_{2}$, we have chosen only PDVB-VI and PDVB-VT since they show high binding for $\mathrm{CO}_{2}$ as compared to pure PDVB. The low energy optimized complexes are shown in Figure $9(\mathrm{a}, \mathrm{b})$. As already observed for the first molecule, the second $\mathrm{CO}_{2}$ also shows a high stability near the $\mathrm{N}$-site of the copolymers with binding energies (calculated using equation 4) $0.01 \mathrm{eV}, 0.08 \mathrm{eV}$ for PDVB-VI and PDVB-VT, respectively.

Adsorbent Recyclability. Up to seven cycles of $\mathrm{CO}_{2}$ adsorption and desorption were performed on PDVB-VT0.7 which indicates high chemical and physical stability (Figure 10). The $\mathrm{CO}_{2}$ adsorption efficiency was maintained at 100\% after the 7th cycle. Figures S5 and S6 confirmed that textural properties (BET isotherms) and functional moieties (FTIR) of PDVB-VT0.7 remain intact after seven cycles of $\mathrm{CO}_{2}$ adsorption and recovery. In the porous adsorbents, inter-particle spaces should be considered under high pressure gas adsorption and storage (pre-combustion process) [90]. However, our work focused on $\mathrm{CO}_{2}$ adsorption under atmospheric pressure (post-combustion process).

\section{Discussion}

Previously reported amine functionalized PDVB by tartardiamide co-monomer[66] with more hydrophilic functionalities of $-\mathrm{OH}$ and $=\mathrm{O}$ might have less moisture resistivity which is detrimental for $\mathrm{CO}_{2}$ adsorption from flue gas. Furthermore, in the earlier works on $\mathrm{CO}_{2}$ adsorption by amine-functionalized PDVB, active adsorption sites, type of adsorption, and the trade-off between functionality and surface area have not been established[65-67]. Finally, adsorptive properties of non-functionalized PDVB have not been studied in comparison with the modified ones which are important to clarify the role of various functionalities.

Here, we systematically studied the surface area and $\mathrm{CO}_{2}$ adsorptive properties of highly hydrophobic PDVB-based materials to illuminate the role of amine rich co-monomers and to identify active sites for $\mathrm{CO}_{2}$ molecules. The $\mathrm{CO}_{2}$ uptake and heat of adsorption of non-functionalized PDVB were compared with the amine-modified ones to investigate the role of different co-monomers with various densities of nitrogen species and the loading amount of nitrogen-rich co-monomers. Water contact angle measurements of PDVB-VT $\left(150^{\circ}\right)[60]$ have shown high hydrophobicity and moisture resistivity which makes this material a good candidate for $\mathrm{CO}_{2}$ removal from flue gas. Utilizing microwave assisted synthesis is helpful in screening various types of polymer modifications since this is much quicker than hydrothermal methods. For microwave assisted synthesis of functionalized PDVB we used $2 \mathrm{~h}$ of heating, while the hydrothermal approach takes about $20 \mathrm{~h}$. Various thermal conditions and reagent concentrations were studied to optimize surface areas of PDVB-VI (Table S1). The best run (entry 21) was used as a starting point for optimizing $\mathrm{CO}_{2}$ adsorption for PDVB-based materials (Table 1). 
The surface area and pore volume dropped about $20 \%$ when co-monomer functionalities (VI or VT) were incorporated into the PDVB structure. In fact, there was a trade-off between textural properties and amine functionality loading. An optimum condition could be obtained where enough amounts of amine functionalities were loaded while surface area and pore volumes were maintained at relatively high levels. Decreasing the amount of initiator led to more elevated surface area[65] partly due to controlling the rate of polymerization and formation of pores while limiting co-monomer incorporation. IR spectroscopy confirmed incorporation of amine species for PDVB-VI and PDVB-VT. According to deconvoluted patterns of N1s for PDVB-VT in XPS analysis, different types of nitrogen atoms corresponding to the triazole ring were observed. The XPS results simultaneously confirmed the incorporation of nitrogen resulting from copolymerization of PDVB with VI and VT and distinguished PDVB-VI from PDVB-VT. Morphological studies of PDVB, PDVB-VI, and PDVB-VT also revealed the porous structure of these materials. However, the SEM image of bare PDVB showed a less dense three-dimensional structure with higher accessible surfaces. SEM images of PDVB-VI and PDVB-VT at high magnification illustrated relative packed structures, and fewer available surfaces than the non-functionalized PDVB. Microstructural analyses of these samples were in good agreement with surface area analysis, which showed that nitrogen incorporation led to declining of the surface area of the polymer.

Extensive theoretical studies have shown that different types of interaction takes place between $\mathrm{CO}_{2}$ on the triazole and imidazole subunits. Dalbouha et al. have shown that there is significant orientation dependence for intermolecular interactions between $\mathrm{CO}_{2}$ and imidazole [91]. The orientation we figured was closer to a $\mathrm{C} 1$ structure comparing to their study which could be due to the side units added in the polymeric environment. Another study which extensively examined configurational analysis between $\mathrm{CO}_{2}$ and triazole showed strong anisotropic interactions [92]. Here we have shown that comparing $\mathrm{CO}_{2}-$ adsorbent interactions with the same level of theory we get stronger interactions with triazole. Nitrogenrich co-monomer of VT resulted in enhancements in the $\mathrm{CO}_{2}$ adsorptive properties due to providing abundant active sites toward $\mathrm{CO}_{2}$ molecules[24]. However, further increase in the amount of VT (PDVBVT0.9) led to reduction in the surface area and pore volume which showed less activity in comparison with PDVB-VT0.7. Although amine functionalities improve the adsorption efficiency, low surface area adversely impacts $\mathrm{CO}_{2}$ adsorption capacity. High selectivity of $\mathrm{CO}_{2}$ over $\mathrm{N}_{2}$ was obtained by the hydrophobic structure of all PDVB materials which was enhanced by amine functionalities (Figure 6). Calculated heats of adsorption $\left(\mathrm{Q}_{\mathrm{st}}\right)$ for all PDVB materials revealed similar changes of $\mathrm{Q}_{\mathrm{st}}$ for $\mathrm{CO}_{2}$ uptake. Higher $\mathrm{Q}_{\mathrm{st}}$ at the beginning of $\mathrm{CO}_{2}$ adsorption is due to stronger interaction between $\mathrm{CO}_{2}$ molecules and adsorbents which resulted from more available active sites[93]. However, as adsorption progressed, the heat of adsorption decreases due to fewer accessible pores and active sites. Electrostatic fields within pores are attributed to $\mathrm{CO}_{2}$ uptake by adsorbent at low coverage of $\mathrm{CO}_{2}$ (low pressure). However, at high coverage of $\mathrm{CO}_{2}$, the interaction between electrostatic field gradients in the adsorbent and the $\mathrm{CO}_{2}$ quadrupole moment is the main factor affecting the adsorption efficiency. Physisorption could be considered for $\mathrm{Q}_{\mathrm{st}}$ less than $80 \mathrm{kJmol}^{-1}$, while for $\mathrm{Q}_{\mathrm{st}}$ of $80-200 \mathrm{kJmol}^{-1}$, chemisorption of $\mathrm{CO}_{2}$ is dominant[94]. Onset pressure calculations based on IAR diagrams, indicated that more nitrogen-rich amine functionality of VT provided higher energy of active sites. All PDVB materials showed $\mathrm{Q}_{\text {st }}$ less than $80 \mathrm{kJmol}^{-1}$ which are attributed to a more physical adsorption pathway. Our computational studies reveal that the presence of a model with adsorbed $\mathrm{CO}_{2}$ reduces the adsorption energy of the second $\mathrm{CO}_{2}$ on the copolymer complex. However, PDVB-VT still maintains the trend of high adsorption capacity for $\mathrm{CO}_{2}$ than PDVB-VI due to the more amine-rich structure. 


\section{Conclusions}

We utilized microwave assisted synthesis to optimize surface area and functionality of thermally and chemically stable porous PDVB for ecological sustainability through $\mathrm{CO}_{2}$ adsorption. The amine incorporation into PDVB was confirmed by FTIR and XPS for both imidazole and triazole based comonomers. Different densities of amine in each co-monomer led to various textural properties and adsorption capacities. With more amine functionalities loaded into PDVB, lower surface areas and pore volumes were obtained. The optimization of the amount of amine functionalities and initiator regarding $\mathrm{CO}_{2}$ adsorption, led to high adsorption efficiency while achieving relatively high surface areas and pore volumes. The $\mathrm{CO}_{2}$ adsorptive properties of PDVB were enhanced more than $116 \%$ by the optimized synthesis condition of more amine rich functionality (VT) into the mesoporous polymer (PDVB-VT0.7IN0.07). Calculated heat of adsorption showed physical adsorption of $\mathrm{CO}_{2}$ molecules by PDVB based adsorbents. Isothermal adsorbate retention also showed that VT incorporation provides active sites with higher energy to capture $\mathrm{CO}_{2}$. Computational studies confirm that the triazole ring has a higher capacity of attracting $\mathrm{CO}_{2}$ as compared to the imidazole ring.

\section{Acknowledgements}

This work was supported by US Department of Energy, Office of Basic Energy Sciences, Division of Chemical, Biological and Geological Sciences under grant DE-FG02- 86ER13622.A000 Authors would also like to acknowledge the Biosciences Electron Microscopy Facility of the University of Connecticut.

\section{References}

[1] N.A. Rashidi, S. Yusup, An overview of activated carbons utilization for the post-combustion carbon dioxide capture, J. CO2 Util. 13 (2016) 1-16. doi:10.1016/j.jcou.2015.11.002.

[2] K. Sumida, D.L. Rogow, J. a Mason, T.M. Mcdonald, E.D. Bloch, Z.R. Herm, et al., Carbon Dioxide Capture in Metal À Organic Frameworks, Chem. Rev. 112 (2012) 724-781. doi: $10.1021 / \mathrm{cr} 2003272$.

[3] Ipcc, Contribution of Working Group I to the Third Assessment Report of the Intergovernmental Panel on Climate Change, 2001. doi:10.1256/004316502320517344.

[4] IPCC WGI AR5, Climate Change 2013: The Physical Science Basis, Ipcc. (2013) 31. doi:10.1017/CBO9781107415324.

[5] T.F. Wall, Combustion processes for carbon capture, Proc. Combust. Inst. 31 I (2007) 31-47. doi:10.1016/j.proci.2006.08.123.

[6] L. Espinal, D.L. Poster, W. Wong-Ng, A.J. Allen, M.L. Green, Measurement, standards, and data needs for CO2 capture materials: A critical review, Environ. Sci. Technol. 47 (2013) 1196011975. doi:10.1021/es402622q.

[7] H. Yang, Z. Xu, M. Fan, R.B. Slimane, A.E. Bland, I. Wright, Progress in carbon dioxide seperation and capture: A review, J. Environ. Sci. 20 (2008) 14-27. http://ac.elscdn.com/S1001074208600029/1-s2.0-S1001074208600029-main.pdf_tid=bf61e062-9c7e-11e3a4c3-00000aab0f27\&acdnat=1393155574_02fc5a378882cfa3956ac4d3287e4c7f.

[8] A. Samanta, A. Zhao, G.K.H. Shimizu, P. Sarkar, R. Gupta, Post-combustion CO 2 capture using 
solid sorbents: A review, Ind. Eng. Chem. Res. 51 (2012) 1438-1463. doi:10.1021/ie200686q.

[9] C.-C. Hwang, J.J. Tour, C. Kittrell, L. Espinal, L.B. Alemany, J.M. Tour, Capturing carbon dioxide as a polymer from natural gas, Nat. Commun. 5 (2014) 3961. doi:10.1038/ncomms4961.

[10] S.S. Kapdi, V.K. Vijay, S.K. Rajesh, R. Prasad, Biogas scrubbing, compression and storage: Perspective and prospectus in Indian context, Renew. Energy. 30 (2005) 1195-1202. doi:10.1016/j.renene.2004.09.012.

[11] S. Satyapal, T. Filburn, J. Trela, J. Strange, Performance and properties of a solid amine sorbent for carbon dioxide removal in space life support applications, Energy and Fuels. 15 (2001) 250255. doi:10.1021/ef0002391.

[12] S. Builes, P. López-Aranguren, J. Fraile, L.F. Vega, C. Domingo, Analysis of CO 2 Adsorption in Amine-Functionalized Porous Silicas by Molecular Simulations, Energy \& Fuels. 29 (2015) 38553862. doi:10.1021/acs.energyfuels.5b00781.

[13] G. Chang, L. Yang, J. Yang, Y. Huang, K. Cao, J. Ma, et al., A nitrogen-rich, azaindole-based microporous organic network: synergistic effect of local dipole- $\pi$ and dipole-quadrupole interactions on carbon dioxide uptake, Polym. Chem. 7 (2016) 5768-5772. doi:10.1039/C6PY01154C.

[14] M. Auta, M. Umaru, M.D. Yahya, O.D. Adeniyi, I.M. Aris, B. Suleiman, Diethanolamine Functionalized Waste Tea Activated Carbon for CO2 Adsorption, (2015).

[15] R. V. Siriwardane, M.S. Shen, E.P. Fisher, J.A. Poston, Adsorption of CO2 on molecular sieves and activated carbon, Energy and Fuels. 15 (2001) 279-284. doi:10.1021/ef000241s.

[16] C. a. Grande, Advances in Pressure Swing Adsorption for Gas Separation, ISRN Chem. Eng. 2012 (2012) 1-13. doi:10.5402/2012/982934.

[17] S. Choi, J.H. Drese, C.W. Jones, Adsorbent materials for carbon dioxide capture from large anthropogenic point sources, ChemSusChem. 2 (2009) 796-854. doi:10.1002/cssc.200900036.

[18] K. Kim, J.W. Han, K.S. Lee, W.B. Lee, Promoting alkali and alkaline-earth metals on MgO for enhancing CO2 capture by first-principles calculations, Phys. Chem. Chem. Phys. 16 (2014) 24818-24823. doi:10.1039/C4CP03809F.

[19] S.M. Mahurin, J. Górka, K.M. Nelson, R.T. Mayes, S. Dai, Enhanced CO2/N2 selectivity in amidoxime-modified porous carbon, Carbon N. Y. 67 (2014) 457-464.

http://www.sciencedirect.com/science/article/pii/S0008622313009652 (accessed January 7, 2015).

[20] K. Li, J. Jiang, S. Tian, F. Yan, X. Chen, Polyethyleneimine-nano silica composites: a low-cost and promising adsorbent for COln $2 \backslash n$ capture, J. Mater. Chem. A. 3 (2015) 2166-2175. doi:10.1039/C4TA04275A.

[21] N. Gargiulo, A. Peluso, P. Aprea, F. Pepe, D. Caputo, D. Ingegneria, et al., CO 2 Adsorption on Polyethylenimine-Functionalized SBA-15 Mesoporous Silica : Isotherms and Modeling, J. Chem. Eng. Data. 59 (2014) 896-902.

[22] M.R. Hudson, W.L. Queen, J.A. Mason, D.W. Fickel, R.F. Lobo, C.M. Brown, Unconventional, highly selective CO 2 adsorption in zeolite SSZ-13, J. Am. Chem. Soc. 134 (2012) 1970-1973. doi:10.1021/ja210580b. 
[23] Z. Zhang, Z.-Z. Yao, S. Xiang, B. Chen, Perspective of microporous metal-organic frameworks for CO 2 capture and separation, Energy Environ. Sci. 7 (2014) 2868.

http://pubs.rsc.org/en/content/articlehtml/2014/ee/c4ee00143e (accessed November 25, 2014).

[24] K. Wang, H. Huang, D. Liu, C. Wang, J. Li, C. Zhong, Covalent Triazine-Based Frameworks with Ultramicropores and High Nitrogen Contents for Highly Selective CO2 Capture, Environ. Sci.

Technol. 50 (2016) 4869-4876. doi:10.1021/acs.est.6b00425.

[25] S. Xiong, X. Fu, L. Xiang, G. Yu, J. Guan, Z. Wang, et al., Liquid acid-catalysed fabrication of nanoporous 1,3,5-triazine frameworks with efficient and selective CO2 uptake, Polym. Chem. 5 (2014) 3424. doi:10.1039/c3py01471a.

[26] Martunus, Z. Helwani, A.D. Wiheeb, J. Kim, M.R. Othman, Improved carbon dioxide capture using metal reinforced hydrotalcite under wet conditions, Int. J. Greenh. Gas Control. 7 (2012) 127-136. doi:10.1016/j.ijggc.2012.01.007.

[27] Z.H. Lee, K.T. Lee, S. Bhatia, A.R. Mohamed, Post-combustion carbon dioxide capture: Evolution towards utilization of nanomaterials, Renew. Sustain. Energy Rev. 16 (2012) 2599-2609. doi:10.1016/j.rser.2012.01.077.

[28] R. Besson, M. Rocha Vargas, L. Favergeon, CO 2 adsorption on calcium oxide: An atomic-scale simulation study, Surf. Sci. 606 (2012) 490-495. doi:10.1016/j.susc.2011.11.016.

[29] T. Jiang, W. Zhong, T. Jafari, S. Du, J. He, Y.-J. Fu, et al., Siloxane D4 adsorption by mesoporous aluminosilicates, Chem. Eng. J. (2016). doi:10.1016/j.cej.2015.12.094.

[30] T. Jafari, T. Jiang, W. Zhong, N. Khakpash, B. Deljoo, M. Aindow, et al., Modified Mesoporous Silica for Efficient Siloxane Capture, Langmuir. 32 (2016) 2369-2377. doi:10.1021/acs.langmuir.5b04357.

[31] C. Chen, D.W. Park, W.S. Ahn, CO2 capture using zeolite 13X prepared from bentonite, Appl. Surf. Sci. 292 (2014) 63-67. doi:10.1016/j.apsusc.2013.11.064.

[32] O. Cheung, Z. Bacsik, Q. Liu, A. Mace, N. Hedin, Adsorption kinetics for CO2 on highly selective zeolites NaKA and nano-NaKA, Appl. Energy. 112 (2013) 1326-1336. doi:10.1016/j.apenergy.2013.01.017.

[33] G. Li, P. Xiao, P.A. Webley, J. Zhang, R. Singh, Competition of CO2/H2O in adsorption based CO2 capture, Energy Procedia. 1 (2009) 1123-1130. doi:10.1016/j.egypro.2009.01.148.

[34] L.S. Ferreira, J.O. Trierweiler, Modeling and simulation of the polymeric nanocapsule formation process, IFAC Proc. Vol. 7 (2009) 405-410. doi:10.1002/aic.

[35] S. Himeno, T. Tomita, K. Suzuki, S. Yoshida, Characterization and selectivity for methane and carbon dioxide adsorption on the all-silica DD3R zeolite, Microporous Mesoporous Mater. 98 (2007) 62-69. doi:10.1016/j.micromeso.2006.05.018.

[36] S. Keskin, T.M. van Heest, D.S. Sholl, Can metal-organic framework materials play a useful role in large-scale carbon dioxide separations, ChemSusChem. 3 (2010) 879-891.

doi:10.1002/cssc.201000114.

[37] A.C. Kizzie, A.G. Wong-Foy, A.J. Matzger, Effect of humidity on the performance of microporous coordination polymers as adsorbents for CO2 capture, Langmuir. 27 (2011) 63686373. doi:10.1021/la200547k. 
[38] Y. Zhao, K.X. Yao, B. Teng, T. Zhang, Y. Han, A perfluorinated covalent triazine-based framework for highly selective and water-tolerant CO2 capture, Energy Environ. Sci. 6 (2013) 3684-3692. doi:10.1039/C3EE42548G.

[39] W. Lu, D. Yuan, J. Sculley, D. Zhao, R. Krishna, H.C. Zhou, Sulfonate-grafted porous polymer networks for preferential Co 2 adsorption at low pressure, J. Am. Chem. Soc. 133 (2011) 1812618129. doi:10.1021/ja2087773.

[40] F. Ragon, B. Campo, Q. Yang, C. Martineau, A.D. Wiersum, A. Lago, et al., Acid-functionalized UiO-66(Zr) MOFs and their evolution after intra-framework cross-linking: structural features and sorption properties, J. Mater. Chem. A. 3 (2015) 3294-3309. doi:10.1039/C4TA03992K.

[41] M.S. Lee, S.J. Park, Silica-coated multi-walled carbon nanotubes impregnated with polyethyleneimine for carbon dioxide capture under the flue gas condition, J. Solid State Chem. 226 (2015) 17-23. doi:10.1016/j.jssc.2015.01.031.

[42] L. Guo, X. Hu, G. Hu, J. Chen, Z. Li, W. Dai, et al., Tetraethylenepentamine modified protonated titanate nanotubes for CO2 capture, Fuel Process. Technol. 138 (2015) 663-669. doi:10.1016/j.fuproc.2015.07.007.

[43] M. Yao, Y. Dong, X. Feng, X. Hu, A. Jia, G. Xie, et al., The effect of post-processing conditions on aminosilane functionalizaiton of mesocellular silica foam for post-combustion $\mathrm{CO} 2$ capture, Fuel. 123 (2014) 66-72. doi:10.1016/j.fuel.2014.01.059.

[44] D. Wang, C. Sentorun-Shalaby, X. Ma, C. Song, High-capacity and low-cost carbon-based "molecular basket" sorbent for CO2 capture from flue gas, Energy and Fuels. 25 (2011) 456-458. doi:10.1021/ef101364c.

[45] C.H. Yu, C.H. Huang, C.S. Tan, A review of $\mathrm{CO} 2$ capture by absorption and adsorption, Aerosol Air Qual. Res. 12 (2012) 745-769. doi:10.4209/aaqr.2012.05.0132.

[46] P. Bollini, N.A. Brunelli, S.A. Didas, C.W. Jones, Dynamics of CO2 adsorption on amine adsorbents. 1. impact of heat effects, Ind. Eng. Chem. Res. 51 (2012) 15145-15152. doi:10.1021/ie301790a.

[47] M.H. Alkordi, R.R. Haikal, Y.S. Hassan, A.-H. Emwas, Y. Belmabkhout, Poly-functional porousorganic polymers to access functionality - $\mathrm{CO} 2$ sorption energetic relationships, J. Mater. Chem. A. 3 (2015) 22584-22590. doi:10.1039/C5TA05297A.

[48] F.-M. Yang, Y. Liu, L. Chen, C.-T. Au, S.-F. Yin, Synthesis of amine-modified solid Fe-Zr adsorbents for $\mathrm{CO}_{2}$ adsorption, J. Chem. Technol. Biotechnol. (2015) n/a-n/a. doi:10.1002/jctb.4827.

[49] M.R. Liebl, J. Senker, Microporous functionalized triazine-based polyimides with high CO 2 capture capacity, Chem. Mater. 25 (2013) 970-980. doi:10.1021/cm4000894.

[50] A.K. Sekizkardes, S. Altarawneh, Z. Kahveci, I. Timur, H.M. El-kaderi, Highly Selective CO 2 Capture by Triazine-Based Benzimidazole- Linked Polymers `lamog 1, Macromolecules. 47 (2014) 8328-8334.

[51] C. Gu, D. Liu, W. Huang, J. Liu, R. Yang, Synthesis of covalent triazine-based frameworks with high CO 2 adsorption and selectivity, Polym. Chem. 6 (2015) 7410-7417.

doi:10.1039/c5py01090j. 
[52] M.W. Hahn, J. Jelic, E. Berger, K. Reuter, A. Jentys, J.A. Lercher, Role of Amine Functionality for CO2 Chemisorption on Silica, J. Phys. Chem. B. 120 (2016) 1988-1995. doi:10.1021/acs.jpcb.5b10012.

[53] D. Wu, F. Xu, B. Sun, R. Fu, H. He, K. Matyjaszewski, Design and preparation of porous polymers, Chem. Rev. 112 (2012) 3959-4015. doi:10.1021/cr200440z.

[54] V.S.P.K. Neti, J. Wang, S. Deng, L. Echegoyen, High and selective CO2 adsorption by a phthalocyanine nanoporous polymer, J. Mater. Chem. A. 3 (2015) 10284-10288. doi:10.1039/C5TA00587F.

[55] M.X. Tan, Y. Zhang, J.Y. Ying, Mesoporous poly(melamine-formaldehyde) solid sorbent for carbon dioxide capture, ChemSusChem. 6 (2013) 1186-1190. doi:10.1002/cssc.201300107.

[56] P. Puthiaraj, S.S. Kim, W.S. Ahn, Covalent triazine polymers using a cyanuric chloride precursor via Friedel-Crafts reaction for $\mathrm{CO}<\mathrm{inf}>2</ \mathrm{inf}>$ adsorption/separation, Chem. Eng. J. 283 (2016) 184-192. doi:10.1016/j.cej.2015.07.069.

[57] S.K. Das, X. Wang, M.M. Ostwal, Y. Zhao, Y. Han, Z. Lai, Highly stable porous covalent triazine-piperazine linked nanoflower as a feasible adsorbent for flue gas $\mathrm{CO} 2$ capture, Chem. Eng. Sci. 145 (2016) 21-30. doi:10.1016/j.ces.2016.02.007.

[58] Feng Bai, and Xinlin Yang, W. Huang, Synthesis of Narrow or Monodisperse Poly(divinylbenzene) Microspheres by Distillation-Precipitation Polymerization, (2004).

[59] K. Kanamori, K. Nakanishi, T. Hanada, Rigid Macroporous Poly(divinylbenzene) Monoliths with a Well-Defined Bicontinuous Morphology Prepared by Living Radical Polymerization, Adv. Mater. 18 (2006) 2407-2411. doi:10.1002/adma.200601026.

[60] W. Zhu, W. Kong, I. Noshadi, L. Zhao, F. Liu, Solvothermal synthesis of nanoporous, polymeric solid bases with controlled wettability and good catalytic activity, Colloids Surfaces A Physicochem. Eng. Asp. 444 (2014) 314-320. doi:10.1016/j.colsurfa.2014.01.004.

[61] T. Jafari, I. Noshadi, N. Khakpash, S.L. Suib, Superhydrophobic and stable mesoporous polymeric adsorbent for siloxane removal: D4 super-adsorbent, J. Mater. Chem. A. 3 (2015) 5023-5030. doi:10.1039/C4TA06593J.

[62] I. Noshadi, B. Kanjilal, T. Jafari, E. Moharreri, N. Khakpash, T. Jiang, et al., Hydrophobic mesoporous adsorbent based on cyclic amine-divinylbenzene copolymer for highly efficient siloxane removal, RSC Adv. 6 (2016) 77310-77320. doi:10.1039/C6RA11382F.

[63] Y. Zhang, S. Wei, Y. He, F. Nawaz, S. Liu, H. Zhang, et al., Solvothermal synthesis of carboxyl and amido functionalized mesoporous resins for water treatments, J. Mater. Chem. 20 (2010) 4609. doi:10.1039/b920273k.

[64] D. Kuzmicz, P. Coupillaud, Y. Men, J. Vignolle, G. Vendraminetto, M. Ambrogi, et al., Functional mesoporous poly(ionic liquid)-based copolymer monoliths: From synthesis to catalysis and microporous carbon production, Polym. (United Kingdom). 55 (2014) 3423-3430. doi:10.1016/j.polymer.2014.04.032.

[65] X. Feng, C. Gao, Z. Guo, Y. Zhou, J. Wang, Pore structure controllable synthesis of mesoporous poly(ionic liquid)s by copolymerization of alkylvinylimidazolium salts and divinylbenzene, RSC Adv. 4 (2014) 23389-23395. doi:10.1039/c4ra03163f. 
[66] P. Bhanja, R. Gomes, A. Bhaumik, N-rich porous organic polymer with suitable donor-donoracceptor functionality for the sensing of nucleic acid bases and $\mathrm{CO}_{2}$ storage application, RSC Adv. 5 (2015) 74916-74923. doi:10.1039/C5RA10423H.

[67] R. Gomes, A. Bhaumik, Highly porous organic polymers bearing tertiary amine group and their exceptionally high CO2 uptake capacities, J. Solid State Chem. 222 (2015) 7-11. doi:10.1016/j.jssc.2014.10.032.

[68] F. Wiesbrock, R. Hoogenboom, U.S. Schubert, Microwave-assisted polymer synthesis: State-ofthe-art and future perspectives, Macromol. Rapid Commun. 25 (2004) 1739-1764. doi:10.1002/marc.200400313.

[69] F. Bensebaa, A.A. Farah, D. Wang, C. Bock, X. Du, J. Kung, et al., Microwave synthesis of polymer-embedded Pt-Ru catalyst for direct methanol fuel cell., J. Phys. Chem. B. 109 (2005) 15339-15344. doi:10.1021/jp0519870.

[70] M.R. Raj, M. Kim, H. Il Kim, G.-Y. Lee, C.W. Park, T. Park, A comparative study on the thermaland microwave-assisted Stille coupling polymerization of a benzodithiophene-based donoracceptor polymer (PTB7), J. Mater. Chem. A. 5 (2017) 3330-3335. doi:10.1039/C6TA09212H.

[71] R. Hoogenboom, R.M. Paulus, Åke Pilotti, U.S. Schubert, Scale-up of Microwave-Assisted Polymerizations in Batch Mode: The Cationic Ring-Opening Polymerization of 2-Ethyl-2oxazoline, Macromol. Rapid Commun. 27 (2006) 1556-1560. doi:10.1002/marc.200600349.

[72] J.M. Sauks, D. Mallik, Y. Lawryshyn, T. Bender, M. Organ, A continuous-flow microwave reactor for conducting high-temperature and high-pressure chemical reactions, Org. Process Res. Dev. 18 (2014) 1310-1314. doi:10.1021/op400026g.

[73] R.M. Paulus, T. Erdmenger, C.R. Becer, R. Hoogenboom, U.S. Schubert, Scale-up of microwaveassisted polymerizations in continuous-flow mode: Cationic ring-opening polymerization of 2ethyl-2-oxazoline, Macromol. Rapid Commun. 28 (2007) 484-491. doi:10.1002/marc.200600756.

[74] J. He, Y. Liu, Y. Meng, X. Sun, S. Biswas, M. Shen, et al., High-rate and long-life of Li-ion batteries using reduced graphene oxide/Co 3 O 4 as anode materials, RSC Adv. 6 (2016) 2432024330. doi:10.1039/C6RA03790A.

[75] J.A. Mason, K. Sumida, Z.R. Herm, R. Krishna, J.R. Long, Evaluating metal-organic frameworks for post-combustion carbon dioxide capture via temperature swing adsorption, Energy Environ. Sci. 4 (2011) 3030. doi:10.1039/c1ee01720a.

[76] R.S. Patil, D. Banerjee, C. Zhang, P.K. Thallapally, J.L. Atwood, Selective CO2 Adsorption in a Supramolecular Organic Framework, Angew. Chemie - Int. Ed. (2016) 4599-4602. doi:10.1002/anie.201600658.

[77] P. Tamilarasan, S. Ramaprabhu, Amine-rich ionic liquid grafted graphene for sub-ambient carbon dioxide adsorption, RSC Adv. 6 (2016) 3032-3040. doi:10.1039/C5RA22029G.

[78] P. Tamilarasan, S. Ramaprabhu, Integration of polymerized ionic liquid with graphene for enhanced CO 2 adsorption, J. Mater. Chem. A. 3 (2015) 101-108. doi:10.1039/C4TA04808C.

[79] J.P. Perdew, W. Yue, Accurate and simple density functional for the electronic exchange energy: Generalized gradient approximation, Phys. Rev. B. 33 (1986) 8800-8802.

[80] G. Kresse, J. Furthmuller, Efficiency of ab-initio total energy calculations for metals and 
semiconductors using a plane-wave basis set, Comput. Mater. Sci. 6 (1996) 15-50. doi:10.1016/0927-0256(96)00008-0.

[81] P.E. Blöchl, Projector augmented-wave method, Phys. Rev. B. 50 (1994) 17953-17979.

[82] M.P. Seah, I.S. Gilmore, G. Beamson, XPS: binding energy calibration of electron spectrometers 5re-evaluation of the reference energies, Surf. Interface Anal. 26 (1998) 642-649. doi:10.1002/(SICI)1096-9918(199808)26:9<642::AID-SIA408>3.0.CO;2-3.

[83] D.J. Miller, M.C. Biesinger, N.S. McIntyre, Interactions of $\mathrm{CO} 2$ and $\mathrm{CO}$ at fractional atmosphere pressures with iron and iron oxide surfaces: One possible mechanism for surface contamination, Surf. Interface Anal. 33 (2002) 299-305. doi:10.1002/sia.1188.

[84] A.P. Dementjev, A. De Graaf, M.C.M. Van de Sanden, K.I. Maslakov, A. V. Naumkin, A.A. Serov, X-ray photoelectron spectroscopy reference data for identification of the C3N4 phase in carbon-nitrogen films, Diam. Relat. Mater. 9 (2000) 1904-1907. doi:10.1016/S09259635(00)00345-9.

[85] Z. Guo, J.K. Cheng, Z. Hu, M. Zhang, Q. Xu, Z. Kang, et al., Metal-organic frameworks (MOFs) as precursors towards $\mathrm{TiO} \times$ /C composites for photodegradation of organic dye, RSC Adv. 4 (2014) 34221-34225. doi:10.1039/C4RA05429F.

[86] A. Vinu, K. Ariga, T. Mori, T. Nakanishi, S. Hishita, D. Golberg, et al., Preparation and characterization of well-ordered hexagonal mesoporous carbon nitride, Adv. Mater. 17 (2005) 1648-1652. doi:10.1002/adma.200401643.

[87] R.F.W. Bader, Atoms in Molecules - A Quantum Theory (International Series of Monographs on Chemistry), New York, 1990.

[88] L. Chen, J.K. Johnson, Formation of odd-numbered clusters of CO2 adsorbed, on nanotube bundles, Phys. Rev. Lett. 94 (2005) 1-4. doi:10.1103/PhysRevLett.94.125701.

[89] C.M. Chang, A. De Leon, P.A. Alvaro, A.F. Jalbout, Theoretical insights on the storage of carbon dioxide using single-walled carbon nanotubes, Comput. Mater. Sci. 63 (2012) 191-196. doi:10.1016/j.commatsci.2012.06.023.

[90] J.P. Marco-Lozar, J. Juan-Juan, F. Suárez-García, D. Cazorla-Amorós, A. Linares-Solano, MOF-5 and activated carbons as adsorbents for gas storage, Int. J. Hydrogen Energy. 37 (2012) 23702381. doi:10.1016/j.ijhydene.2011.11.023.

[91] S. Dalbouha, M. Prakash, V. Timón, N. Komiha, M. Hochlaf, M.L. Senent, Explicitly correlated interaction potential energy profile of imidazole + CO2 complex, Theor. Chem. Acc. 134 (2015) 63. doi:10.1007/s00214-015-1657-z.

[92] R. Boulmène, M. Prakash, M. Hochlaf, Microscopic investigations of site and functional selectivity of triazole for $\mathrm{CO} 2$ capture and catalytic applications, Phys. Chem. Chem. Phys. 18 (2016) 29709-29720. doi:10.1039/C6CP04650A.

[93] V.K. Singh, E. Anil Kumar, Measurement and analysis of adsorption isotherms of CO2 on activated carbon, Appl. Therm. Eng. 97 (2016) 77-86. doi:10.1016/j.applthermaleng.2015.10.052.

[94] X. Zhou, H. Yi, X. Tang, H. Deng, H. Liu, Thermodynamics for the adsorption of SO2, NO and CO2 from flue gas on activated carbon fiber, Chem. Eng. J. 200-202 (2012) 399-404. doi:10.1016/j.cej.2012.06.013. 


\section{Microwave-assisted Synthesis of Amine Functionalized Mesoporous Polydivinylbenzene for $\mathrm{CO}_{2}$ Adsorption}

Tahereh Jafari, ${ }^{a}$ Ehsan Moharreri ${ }^{\mathrm{a}}$, Panteha Toloueinia ${ }^{\mathrm{a}}$, Alireza Shirazi Amin ${ }^{\mathrm{b}}$, Sanjubala Sahoo ${ }^{\mathrm{a}, \mathrm{c}}$, Nasser Khakpash $^{\mathrm{a}, \mathrm{c}}$, Iman Noshadi ${ }^{\mathrm{d}, \mathrm{e}, \mathrm{f}}$, S. Pamir Alpay ${ }^{\mathrm{a}, \mathrm{c}}$ and Steven L. Suib ${ }^{\mathrm{a}, \mathrm{b}, \mathrm{c}} *$

${ }^{\text {a }}$ Institute of Materials Science, University of Connecticut, 97 North Eagleville Road, Storrs, Connecticut 06269-3136, United States

${ }^{\mathrm{b}}$ Department of Chemistry, University of Connecticut, 55 North Eagleville Road, Storrs, Connecticut 06269-3060, United States

${ }^{c}$ Department of Materials Science and Engineering, University of Connecticut, 97 North Eagleville Road, Storrs, Connecticut 06269-5233, United States

${ }^{\mathrm{d}}$ Department of Chemical and Biomolecular Engineering, University of Connecticut, U-3222, 191 Auditorium Road, Storrs, CT 06269-3222, United States

${ }^{\mathrm{e}}$ Department of Chemical Engineering, Rowan University, Glassboro, NJ, United States

${ }^{\mathrm{f}}$ Harvard-MIT Health Science and Technology, Massachusetts Institute of Technology, 77 Massachusetts Avenue, Cambridge, 02139, United States.

* Corresponding author, Email: steven.suib@uconn.edu 
Table 1. Effect of co-monomers types, co-monomer, and initiator amount on the textural and adsorptive properties of porous PDVB.

\begin{tabular}{|c|c|c|c|c|c|}
\hline & Materials & $\begin{array}{c}\text { Co-monomer/ } \\
\text { Initiator }\end{array}$ & $\begin{array}{c}\text { Surface } \\
\text { area } \\
\left(\mathrm{m}^{2} \mathbf{g}^{-1}\right) \\
\end{array}$ & 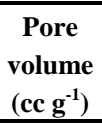 & $\begin{array}{c}\mathrm{CO}_{2} \\
\text { Adsorption } \\
\left(\mathrm{mmol} \mathrm{g}^{-1}\right) \\
\end{array}$ \\
\hline $\mathbf{a}$ & PDVB & - & 789 & 0.97 & 1.23 \\
\hline \multirow{2}{*}{$\begin{array}{c}\text { AIBN } \\
\text { constant }\end{array}$} & PDVB-VI0.7 & VI & 649 & 0.82 & 2.35 \\
\hline & PDVB-VT0.7 & VT & 646 & 0.81 & 2.65 \\
\hline b & PDVB-VT0.2 & $\mathrm{VT}=0.2$ & 697 & 0.88 & 1.39 \\
\hline \multirow{2}{*}{$\begin{array}{c}\text { AIBN } \\
\text { constant }\end{array}$} & PDVB-VT0.7 & $\mathrm{VT}=0.7$ & 646 & 0.81 & 2.65 \\
\hline & PDVB-VT0.9 & $\mathrm{VT}=0.9$ & 500 & 0.67 & 1.49 \\
\hline c & PDVB-VT-IN0.0065* & $\mathrm{IN}=0.0065$ & N/A & N/A & N/A \\
\hline \multirow{3}{*}{$\begin{array}{c}\text { VT } \\
\text { constant }\end{array}$} & PDVB-VT-IN0.03 & $\mathrm{IN}=0.030$ & 815 & 1.9 & 1.48 \\
\hline & PDVB-VT-IN0.07 & $\mathrm{IN}=0.070$ & 646 & 0.81 & 2.65 \\
\hline & PDVB-VT-IN0.09 & $\mathrm{IN}=0.090$ & 559 & 0.61 & 1.39 \\
\hline
\end{tabular}

* The same sample as entry 21 in the Table $\mathrm{S} 1$ with the highest surface area is used as a starting point for $\mathrm{CO}_{2}$ adsorption optimization. 


\section{Microwave-assisted Synthesis of Amine Functionalized Mesoporous Polydivinylbenzene for $\mathrm{CO}_{2}$ Adsorption}

Tahereh Jafari, ${ }^{a}$ Ehsan Moharreri ${ }^{\mathrm{a}}$, Panteha Toloueinia ${ }^{\mathrm{a}}$, Alireza Shirazi Amin ${ }^{\mathrm{b}}$, Sanjubala Sahoo ${ }^{\mathrm{a}, \mathrm{c}}$, Nasser Khakpash $^{\mathrm{a}, \mathrm{c}}$, Iman Noshadi ${ }^{\mathrm{d}, \mathrm{e}, \mathrm{f}}$, S. Pamir Alpay ${ }^{\mathrm{a}, \mathrm{c}}$ and Steven L. Suib ${ }^{\mathrm{a}, \mathrm{b}, \mathrm{c}} *$

${ }^{\text {a }}$ Institute of Materials Science, University of Connecticut, 97 North Eagleville Road, Storrs, Connecticut 06269-3136, United States

${ }^{\mathrm{b}}$ Department of Chemistry, University of Connecticut, 55 North Eagleville Road, Storrs, Connecticut 06269-3060, United States

${ }^{c}$ Department of Materials Science and Engineering, University of Connecticut, 97 North Eagleville Road, Storrs, Connecticut 06269-5233, United States

${ }^{\mathrm{d}}$ Department of Chemical and Biomolecular Engineering, University of Connecticut, U-3222, 191 Auditorium Road, Storrs, CT 06269-3222, United States

${ }^{\mathrm{e}}$ Department of Chemical Engineering, Rowan University, Glassboro, NJ, United States

${ }^{\mathrm{f}}$ Harvard-MIT Health Science and Technology, Massachusetts Institute of Technology, 77 Massachusetts Avenue, Cambridge, 02139, United States.

* Corresponding author, Email: steven.suib@uconn.edu 

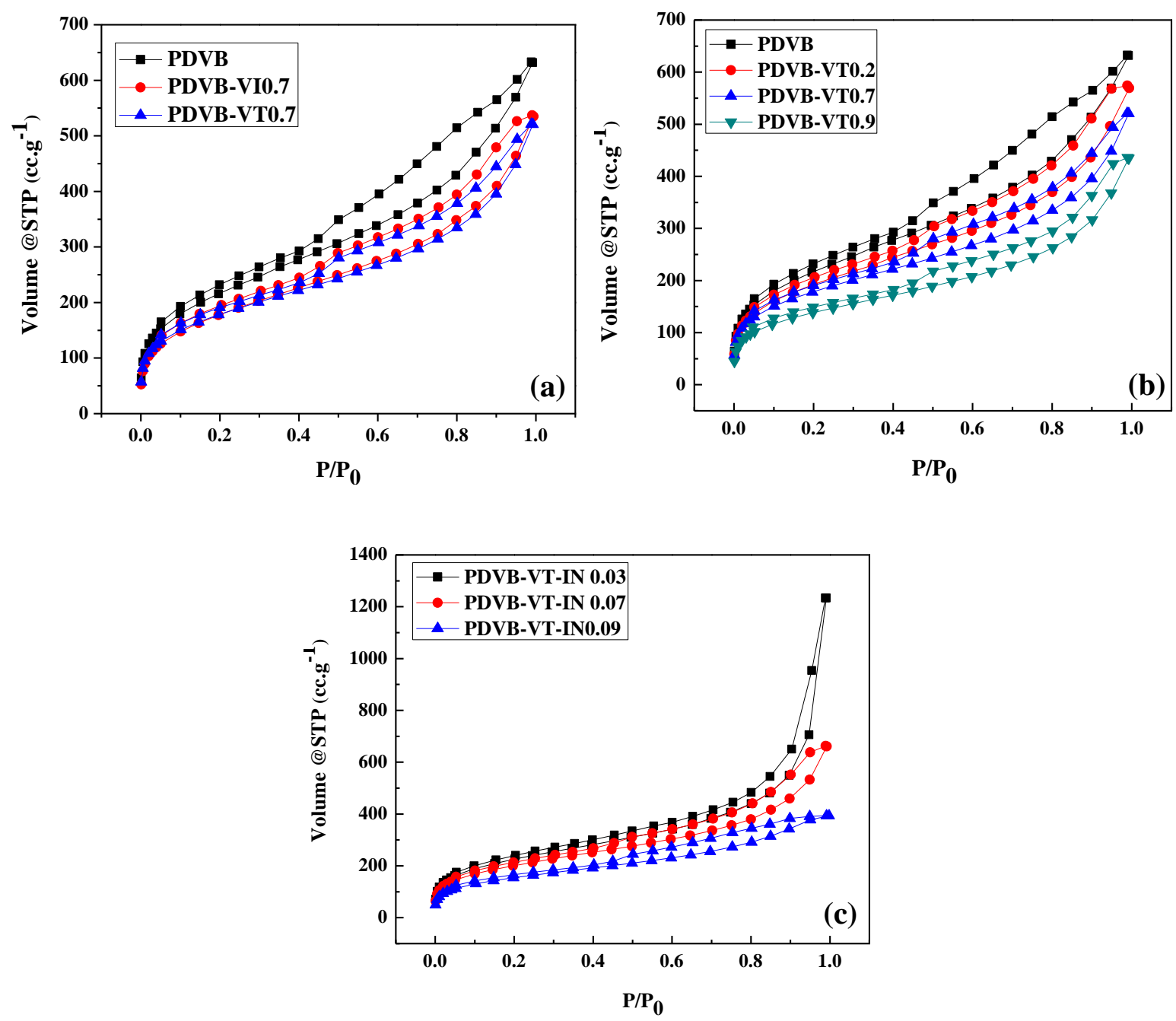

Figure 1. $\mathrm{N}_{2}$ adsorption-desorption isotherms of PDVB a) different co-monomers, b) various amount of co-monomer incorporation, and c) different amount of initiator (AIBN). 

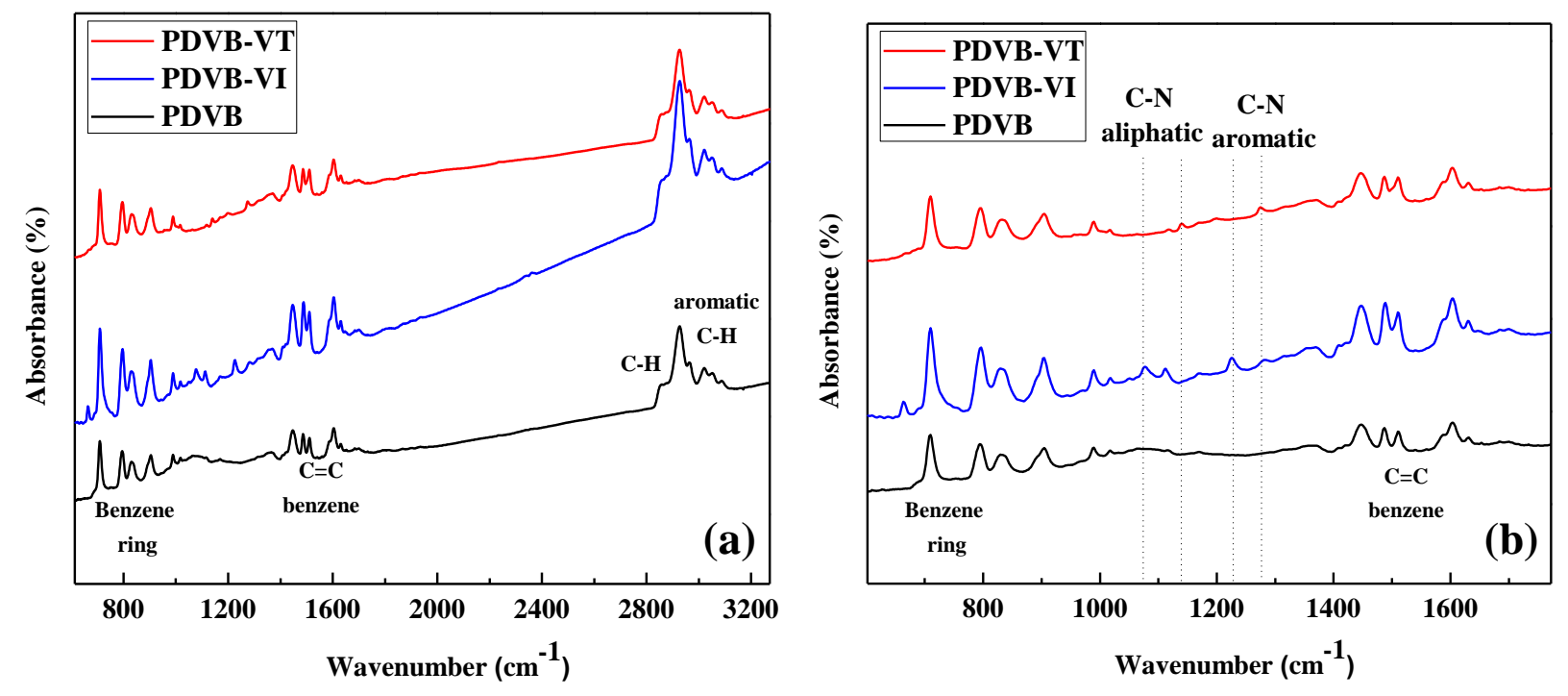

Figure 2. FTIR spectra a) PDVB with and without VI and VT co-monomers, b) same spectra zoomed in $600-1800 \mathrm{~cm}^{-1}$ indicating amine incorporation to the polymer. 

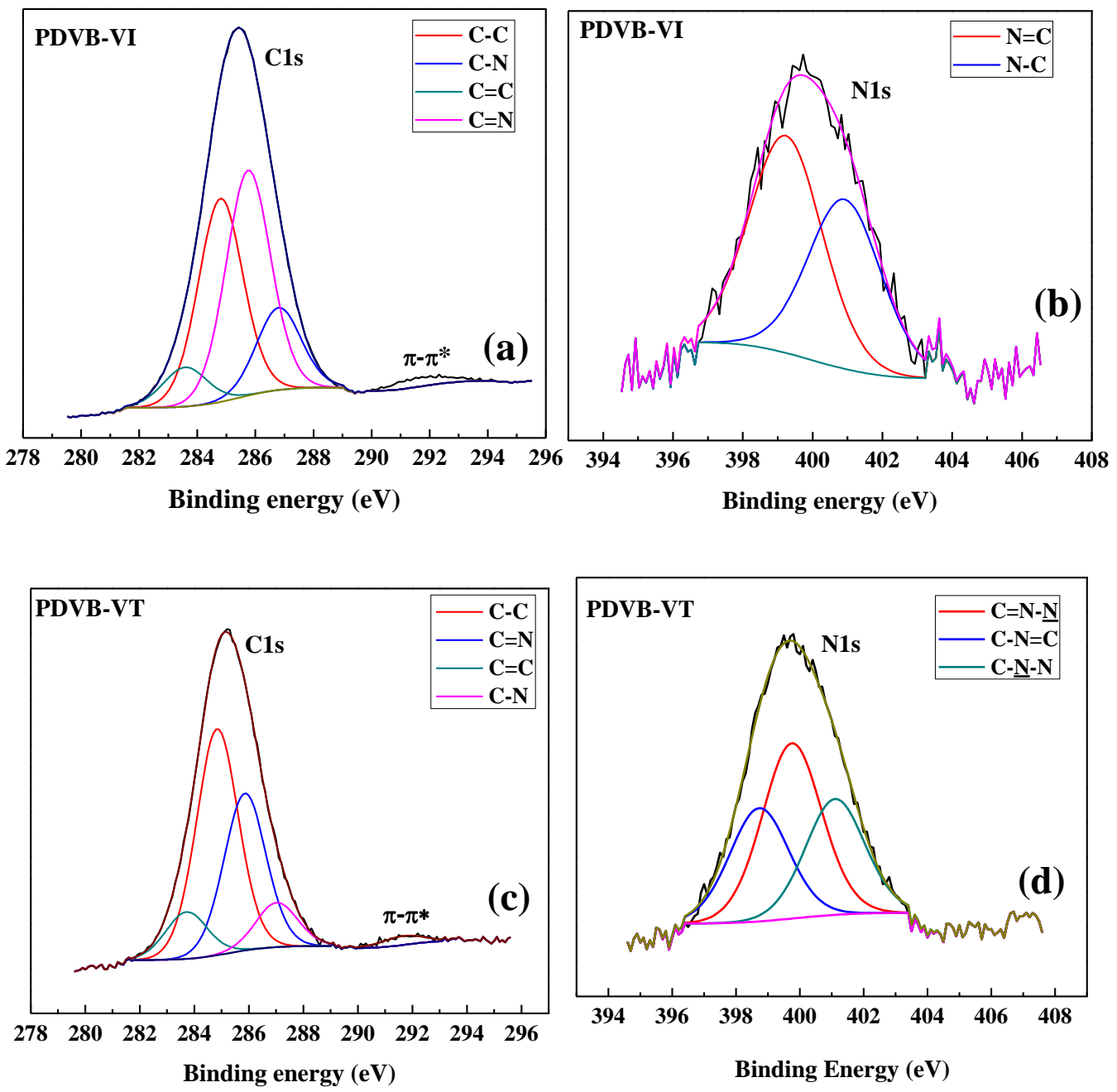

Figure 3. C1s and N1s XPS spectra a, b) PDVB-VI; c,d) PDVB-VT. 

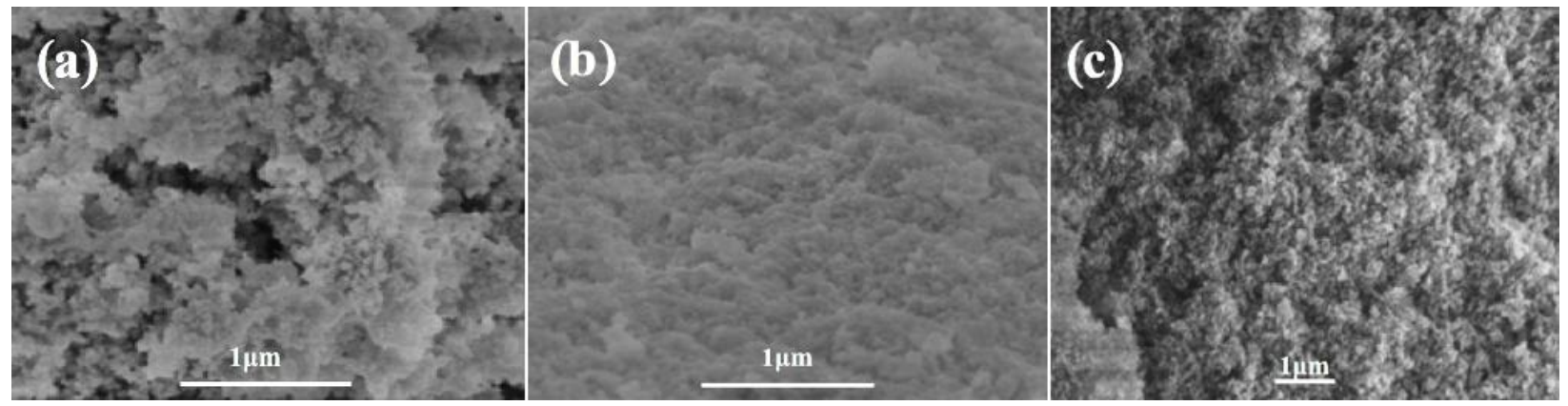

Figure 4. SEM images of a) PDVB, b) PDVB-VI0.7 and c) PDVB-VT0.7. 

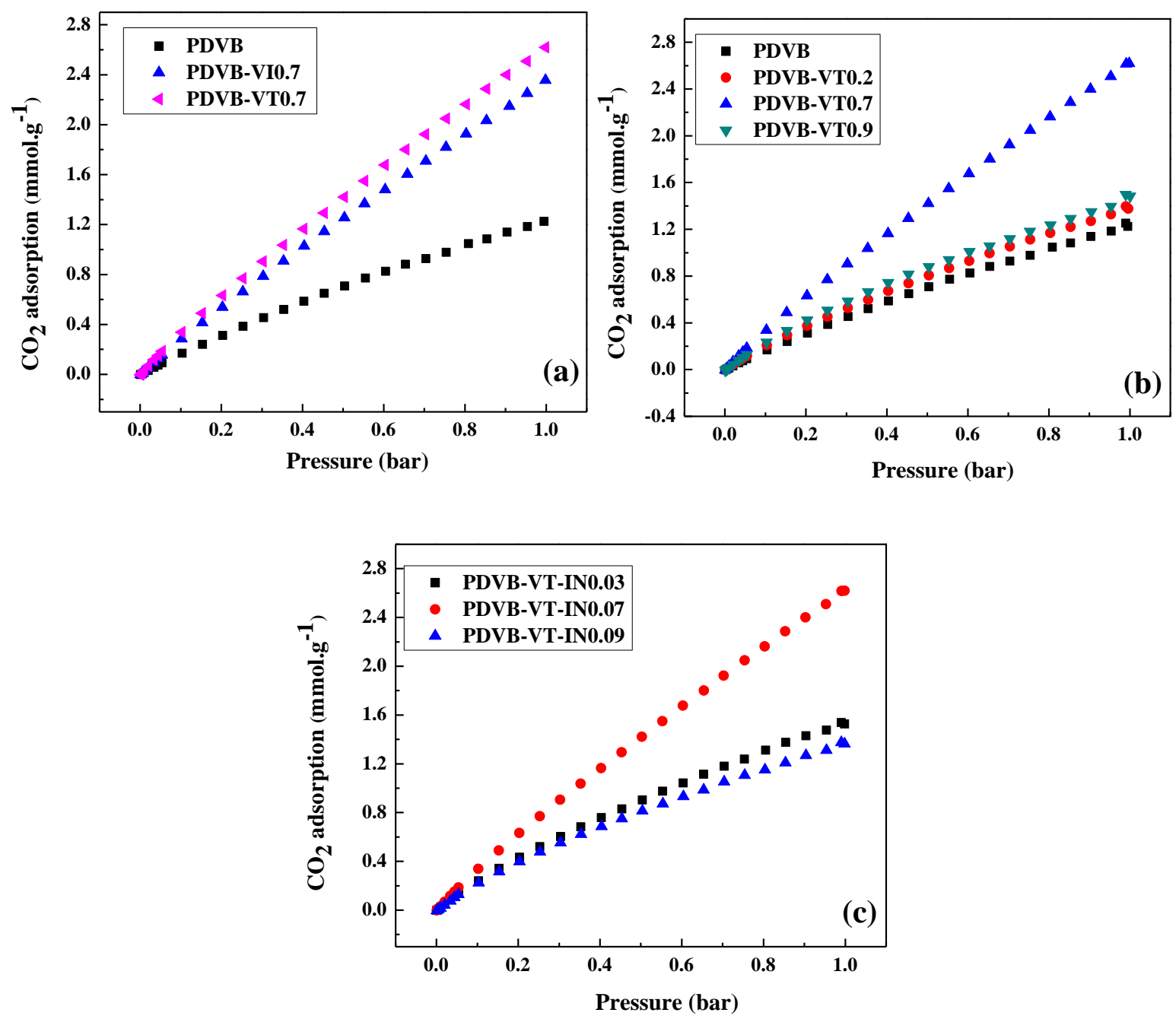

Figure 5. $\mathrm{CO}_{2}$ uptake by a) PDVB with co-monomers of VI and VT, b) PDVB-VT with varied VT amount, c) PDVB-VT with varied initiator (AIBN) amount. 


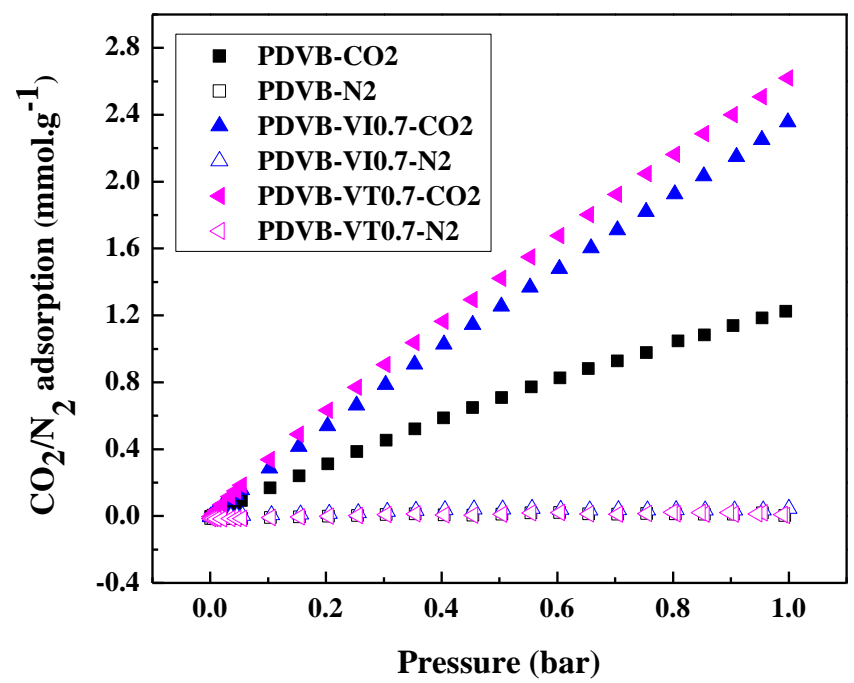

Figure 6. Comparison of $\mathrm{CO}_{2}$ versus $\mathrm{N}_{2}$ adsorption by PDVB adsorbents with different co-monomers at $\mathrm{T}=273{ }^{\circ} \mathrm{K}$. 

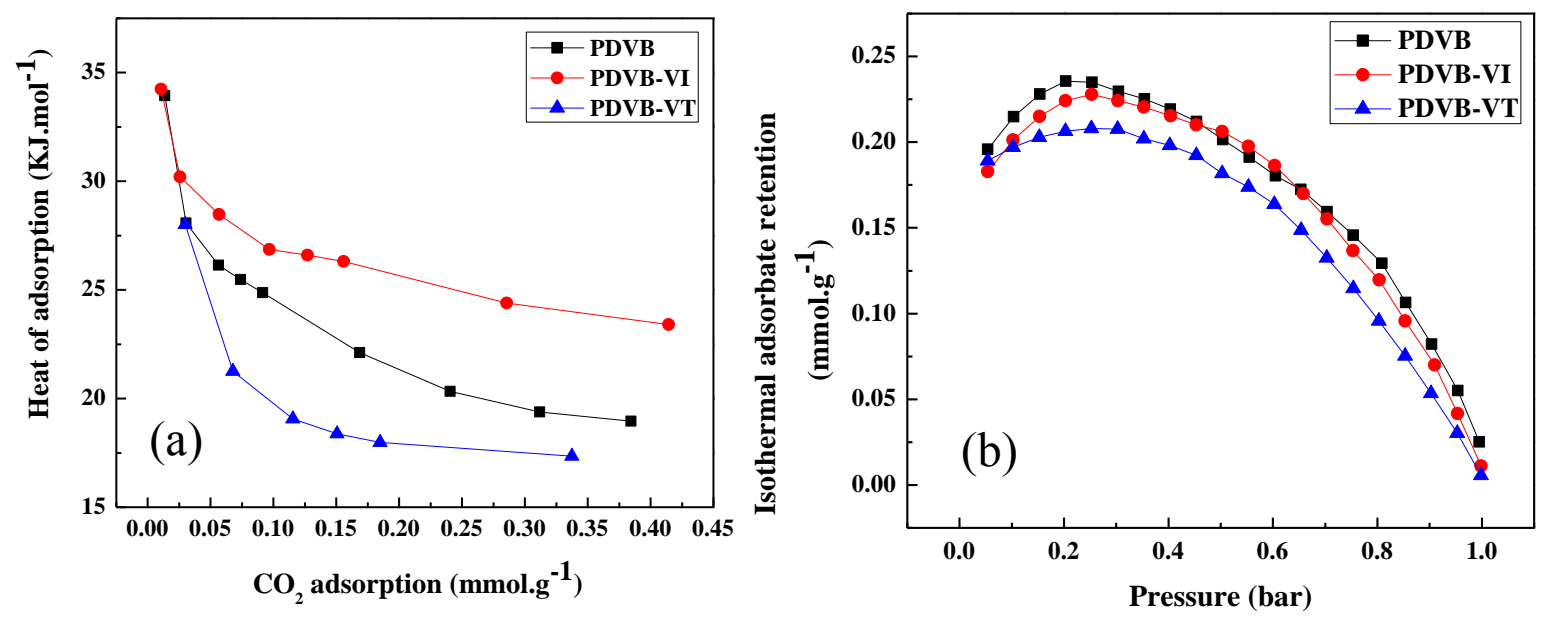

Figure 7. a) Isosteric heat of $\mathrm{CO}_{2}$ adsorption $\left(\mathrm{Q}_{\mathrm{st}}\right)$ on PDVB with co-monomers; b) Isothermal adsorbate retention (IAR) of PDVB adsorbents with different co-monomers. 
(a)

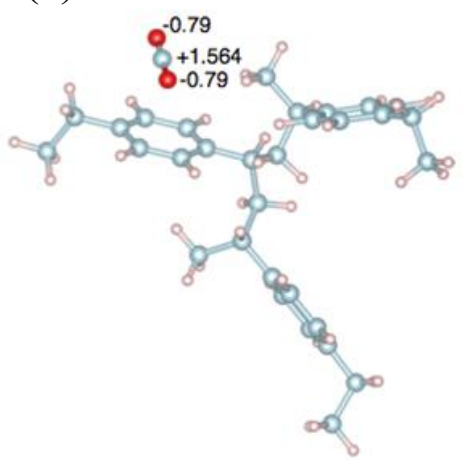

(b)

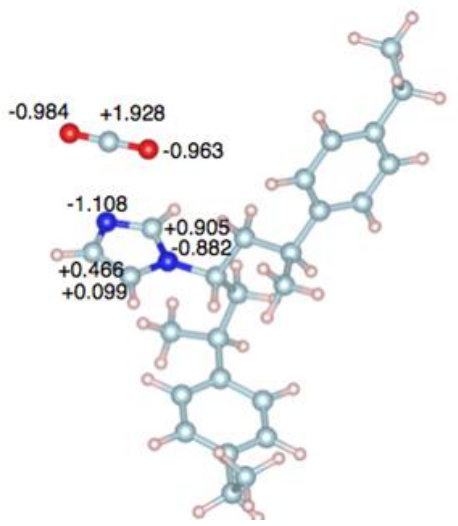

(c)

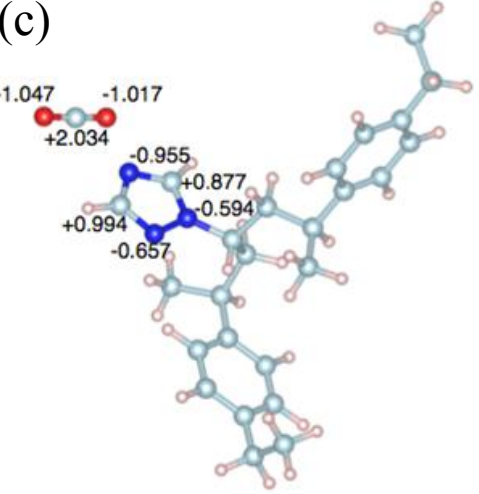

Figure 8. The optimized structures of $\mathrm{CO}_{2}$-polymer complexes. Red, cyan, blue and white balls denote the $\mathrm{O}, \mathrm{C}, \mathrm{N}$ and $\mathrm{H}$ atoms, respectively. The partial charge is calculated using Bader charge analysis. ${ }^{78}$ 
(a)
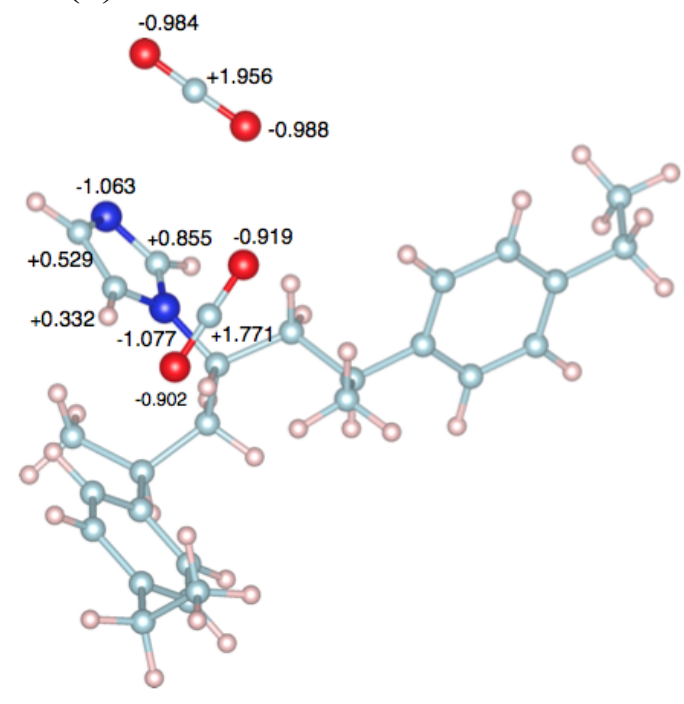

(b)

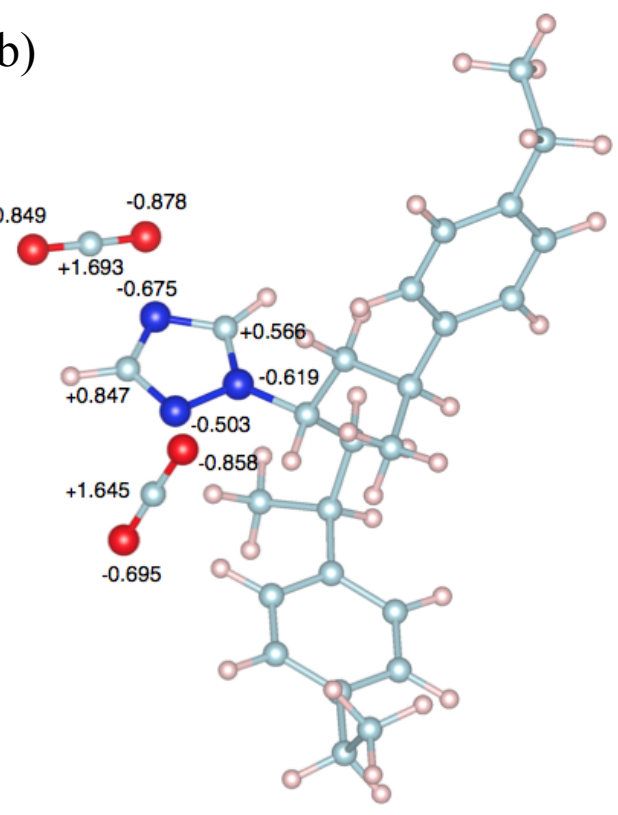

Figure 9. The optimized structures of two $\mathrm{CO}_{2}$ molecules with the copolymer. Red, cyan, blue and white balls denote the $\mathrm{O}, \mathrm{C}, \mathrm{N}$ and $\mathrm{H}$ atoms, respectively. The partial charge is calculated using Bader charge analysis. 


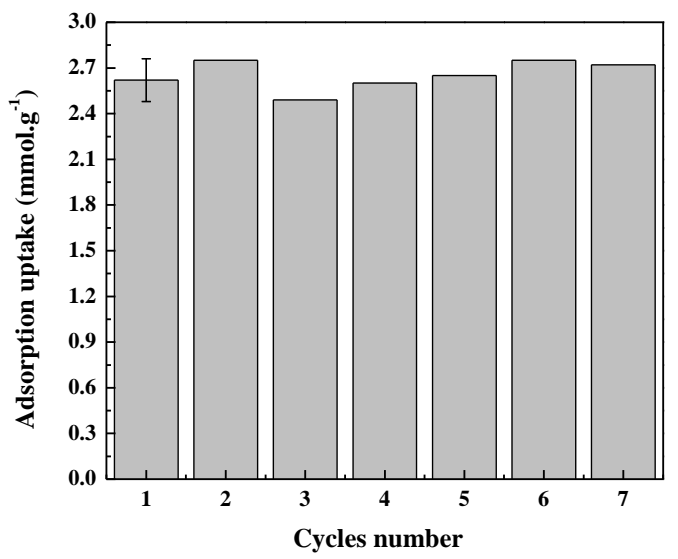

Figure 10. Regeneration of PDVB-VT0.7 for seven cycles (The error bar represents standard deviation of $\pm 0.14 \mathrm{mmolg}^{-1}$ ). 